SF 77

H8

¿opy 1

\section{HANDY BOOK}

ON

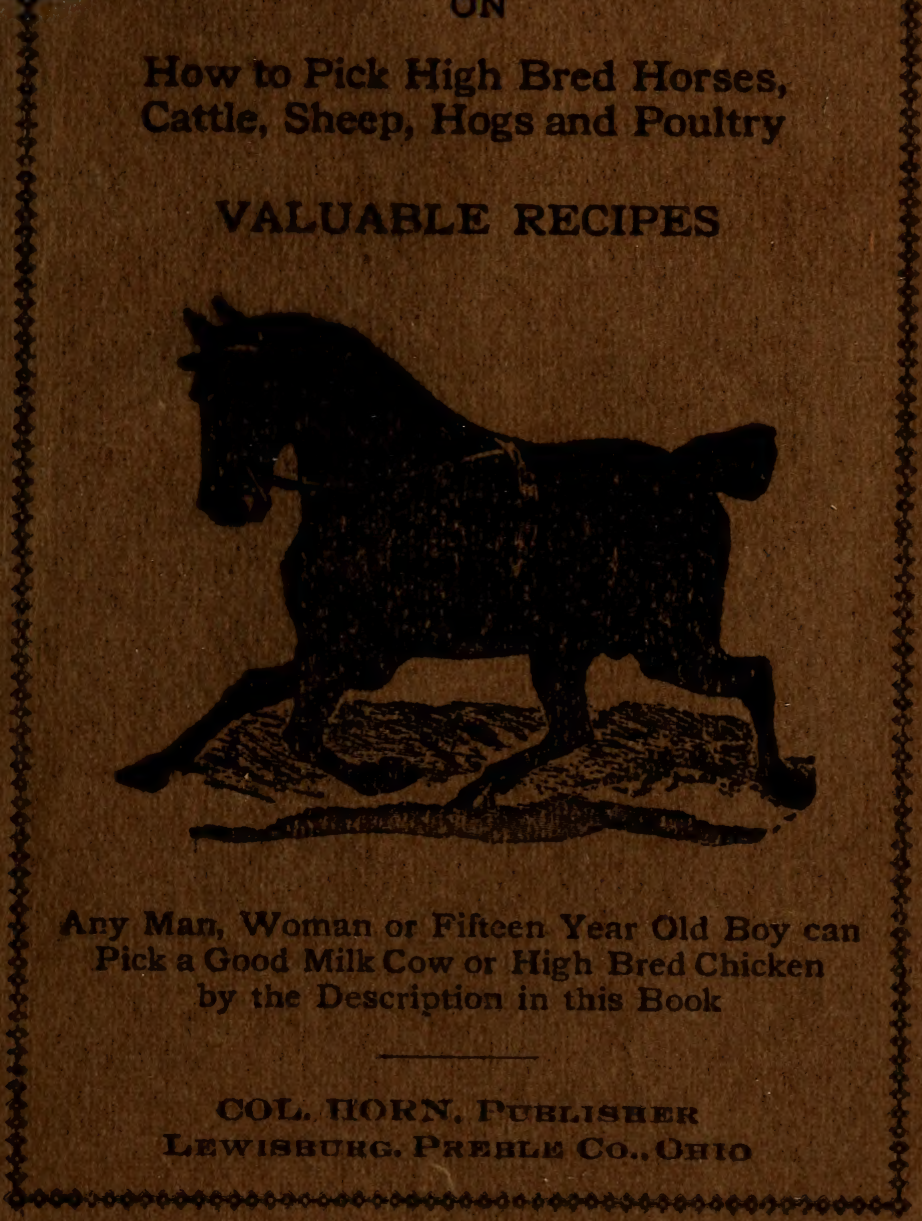




$016 \mathrm{t}$

-OO ONILNIYA SANOWWIL

- ONI "anVTLYOd

0IอI 'TH\&d7

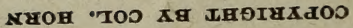




\section{COL. HORN'S}

\section{HANDY BOOK}

ON

How to Pick High Bred Horses, Cat tle, Sheep, Hogs and Poultry

\section{VALUABLE RECIPES}

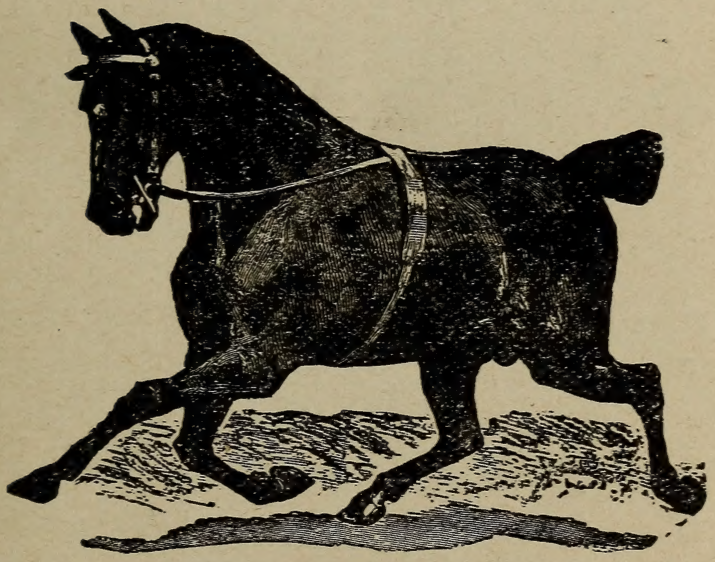

Any Man, Woman or Fifteen Year Old Boy can

Pick a Good Milk Cow or High Bred Chicken by the Description in this Book

COL. HORN, PUBLISHER Lewisburg, Preble Co., Ohio 


$$
\begin{aligned}
& S F 77 \\
& H^{8}
\end{aligned}
$$

(C) CI.A259895

$$
\therefore \vdots
$$




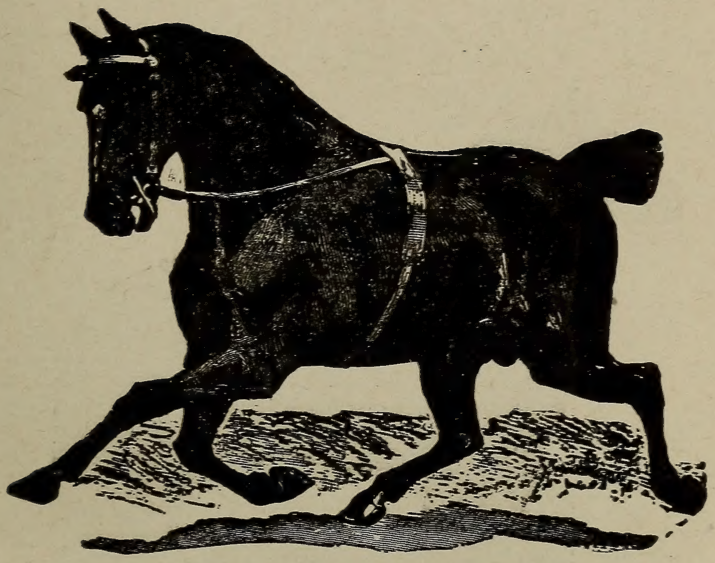

THE GERMAN COACH

They are a fair sized horse and a good huck and knee actor. They are a smooth looking horse and a fair driver. The German Coach are mostly black in color, but sometimes bay.

\section{THE SILVER TAIL MORGAN}

There was a time when the Silver Tail Morgan was a fast horse and some of them are very speedy now. This would be a good track horse to buy. 


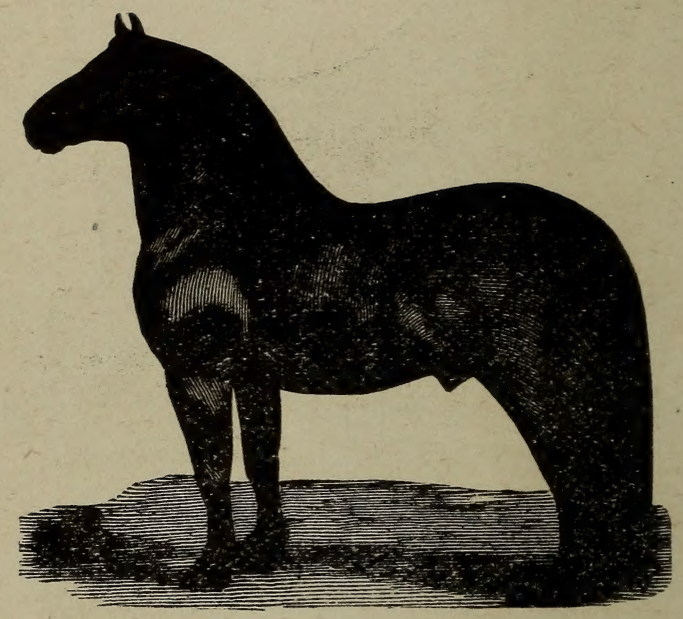

\section{THE PERCHERON HORSE}

The true Percheron was from is to ió hands high and weighed from I 200 to I 400 pounds. The Percheron is a cross breed now and they weigh from iboo to 2000 pounds. They are generally blacks, bays and sometimes grays. The greater part of them are smooth draft horses. 


\section{THE HORSE}

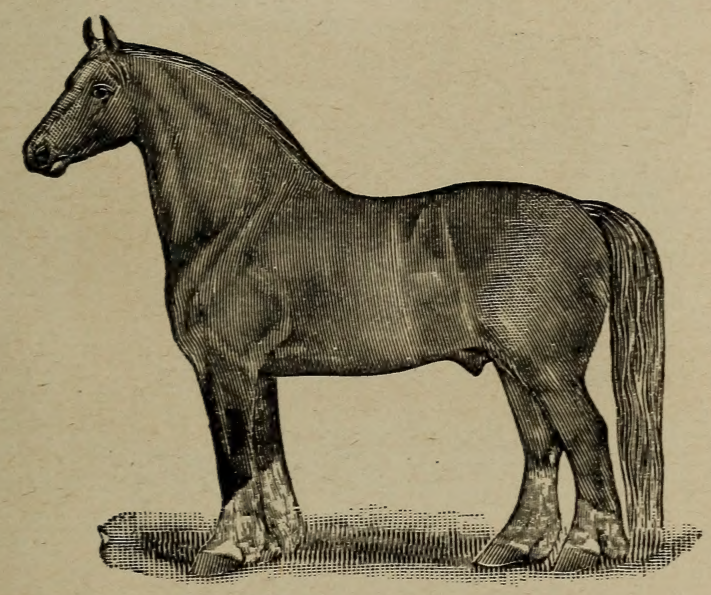

\section{THE SHIRE HORSE}

The Shire is a good sized horse. There are more sorrels than bays. The most of them have four white feet with white on the forehead. 


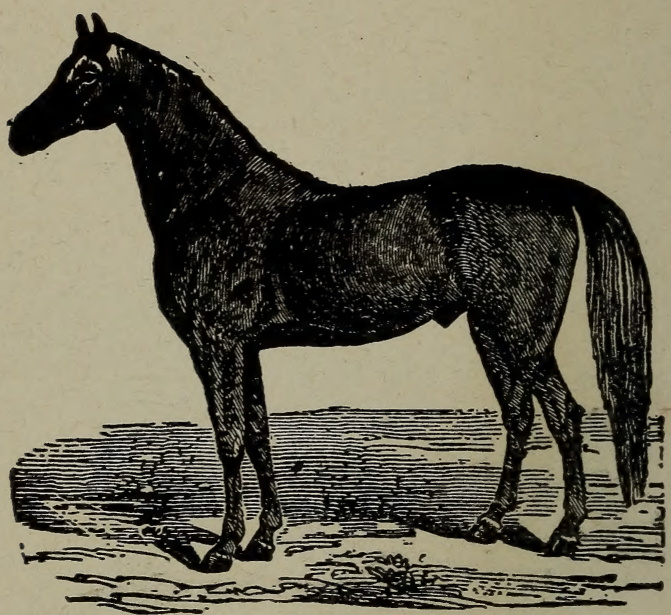

\section{THE CLEVELAND BAY}

It is a carriage horse of good style and action and of good size. They are straight in the pastern joints in front. The top of the ears wide apart. They will breed after their color for three generations. They are also a smooth horse.

\section{THE BLACK HAWK MORGAN}

They are a nice bodied, stylish horse. And a good work horse with a good bone and most of them are gentle for driving purposes. They are the shortest eared horse on the market. 
THE HORSE

7

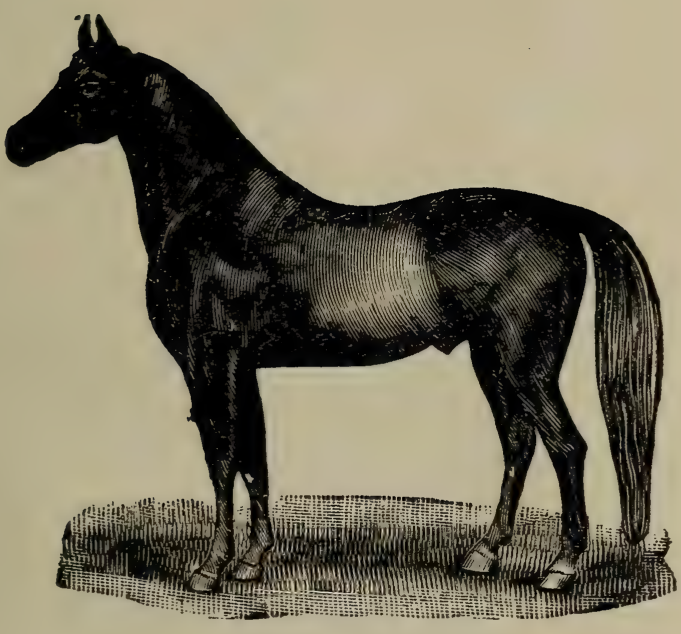

THE HAMBLETONIAN

They make a good driving horse. They are generally of good disposition anu not overly large. The Hambletonian and Wilkes have the same breeding. The way to tell the difference between the two breeds, the Wilkes has a darker limb. 


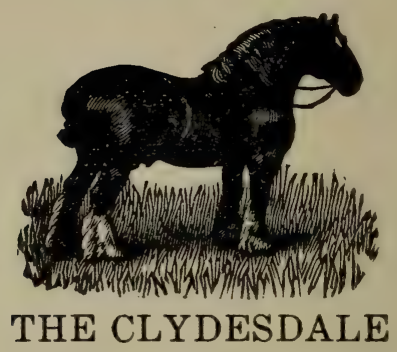

A large horse for draft purposes of strong constitution and easily kept. All colors, generally white feet. A Clydesdale has a flat foot and some of the colts have a weak stifle, too heavy around the heart, thick in the throatlatch, this denotes bad wind; hasn't as good an eye as the Norman horse.

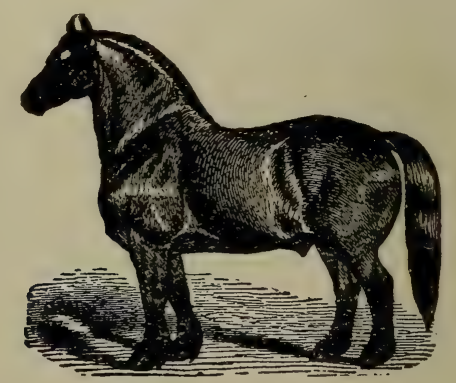

\section{THE NORMAN HORSE}

It is a draft horse, and a fullblooded Norman is a gray. They weigh from I 500 to I 800 pounds. They are a well built horse in power and able to move a heavy load. A Norman has a good foot and not flat. They are a stylish, good boned horse. 


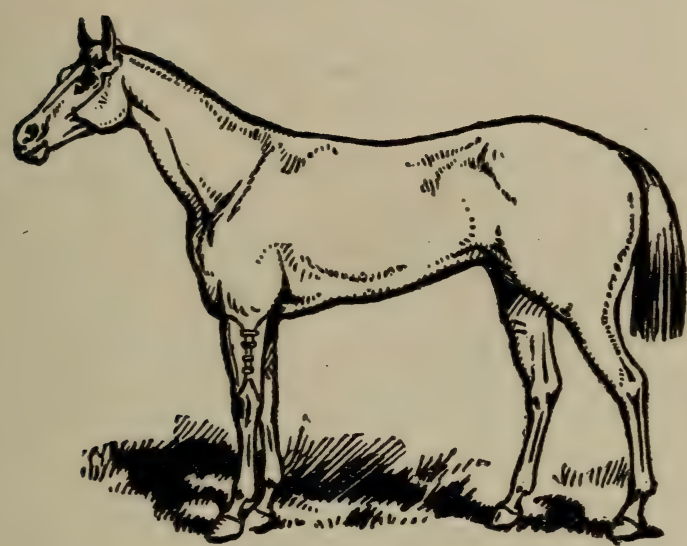

A RUNNING HORSE

The Points tu Look at:-Dish face, thin above the nostrils, a slick eye, heavy at the butt of the ear, the tips of the ears stand in, in the place of out, a long slim neck, slim in the throatlatch, head not too high, the leader that reaches from neck to the shoulder wants to be high from the points of the shoulder, straight in the front legs, straight and short in the pastern joints, a narrow foot and a high heel, narrow in the breast, low withers and short back, not too wide in the kidneys, not to wide in the hips, a little steep in the rump, heavy in the stifle and heavy in the leader that runs from the knee up, a high flank, long in the the belly, straight in the hind legs, short from the pastern joint to the feet, heavy and broad in the knee. 


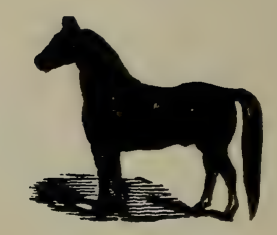

\section{THE SADDLE HORSE}

Puints to Look at For a Saddle Horse: a straight forehead, wide between the eyes, slim ear, long in the neck, the leader that comes from the neck to the shoulder, see that it isn't too near the points of the shoulders, from the points of the shoulders wants to be short, heavy in the withers and not tor) high, heavy and short in the back, wide in the kidneys, hips round and full, a heavy tail bone, a heavy stifle and flank not too low, heary and flat below the knee and a short round pastern joint, short from the pastern joint to the hoof, not too crooked in the hind legs, stand square on his front legs, see that they don't bow back nor forward, not too heavy around the heart nor too wide in the breast. 


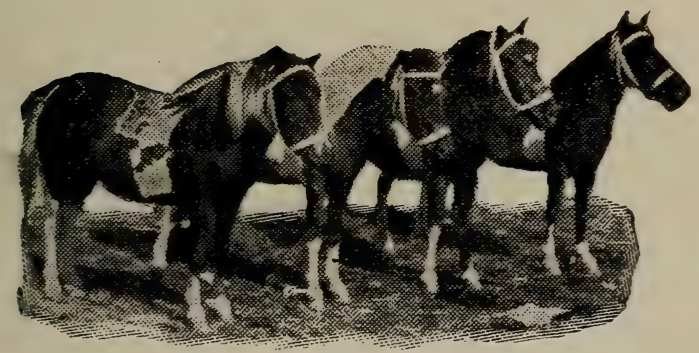

SHETLAND PONIES OF MOST ALL UIFFERENT COLORS

The Shetland Stallion.--Louk for power, heavy mane and tail, extra heavy bone in the tail, short in the back, wide and a little broad across the withers, heavy in the neck, good heavy shoulder, wide between the shoulder, little heavy in the throatlatch, not too narrow in the jaw, the ear heavy and short at the butt, not too narrow between the ears, wide below the ears, wide between the eyes, the forehead wide, not too narrow across the mouth and nostrils, good heavy bone, good heavy front knee, fairly heavy and short in the pastern joints, black foot in the place of a white one, not too narrow in the heel, wide in the kidneys, the hips square across 
and not too rounding, low in the flank, extra heavy in the stifle, wide below the stifle, wide and flat in the hind knee, a wide bone, not too much flesh in front of the pastern joints. These points are for power on a Shetland pony. Look for the sure breeding points as on the stallion for any breed.

\section{A SHETLAND BROOD MARE}

Long in the back, wide in the hips and not too straight, a low flank, long in the belly, not to wide across the heart, thin in the throatlatch. Always buy the brood mare in foal if over ten years of age, for if you don't the chances are the mare will not raise any colts. Look for the same points as on the stallion, outside the sure breeding points.

The Poinis to Look at in Buring a Horse.-Look down at the feet as well as up at the body, first notice the bottom of the feet. Thrush and foot evil is what decays the frog.

Sidebone comes on both sides of the foot and grows on the inside of the hoof 


\section{THE HORSE}

and shows on top of the hoof. Ringbone or side bone either will lame a horse. Ringbone ard sidebone are both caused from a sprain. Ringbone will lame a horse when it grows over that hole that is straight up from the toe right on top of the hoof. That hole comes on all of the feet. Next a horse should stand squarely on his feet, not too narrow nor too low in the heel. The foot should not crook out or in. If a horse has been lame the fever will stop the growth of the foot at the top. The longer he has been lame the smaller the foot will $b \leq$ at the top. See that the feet are both alike, pastern joint and knees, and not too near cut off below the knee. A horse should stand with his feet close together, not stretched cut, nor picking his feet up and setting them out. This shows that the foot is sore. Look for splint on the inside and outside of the leg just below the knee, not too much fles in front of the pastern joints on the hind leg for that is the kind that knuckles, a wide knee and a flat bone and a little wide below the knee. See that the hocks are both alike. 
Thoroughpin is a growth that pushes from one side to the other through the hock. See that one pastern joint is not lower than the other. Always move a horse from you so you can see that they carry their tail straight, see that he has good hock action and shows the bottom of his shoes. Move a horse toward you to see that he is a good knee actor. Back a horse and if he picks his feet up he is all right, and if he drags his feet he is sore in the shoulders. See that the hoofs are both alike and see that they don't crook out or in. How to tell a dummy horse, rub your foot from the pastern joint down; the duller they are in their leg the slower they are to pick their feet up.

Thoroughpin comes through the hock, bog spavin inside of the leg. Blood spavin comes in front from a puff. Bone spavin comes in three places: one grows back the other grows where the regular spavin comes, the other comes in front and shows first under the vein.

See that a horse is wide across the stifle and wide below the stifle. See that the 
stifles are both alike and that their isn't a lump on one and pushes out when he is moved. All speed horses and driving horses should have a high flank so they will gaunt when they are moved. Look for low hip. See that the hips are both alike. See that the hair is not pushed up on one side and smoothed down on the other, for that would make a quarter of an inch difference. See that the hair is smooth on both sides. The same way with a curb. The hair can be turne ${ }^{3}$ up above and below to hide the curb.

A driving horse wants to be narrow in the breast, not extra long in the back, a little steep in the rump. A colt wants to te wider in front than he is behind, a good muscle on the stifle so he will line up when he gets his growth.

These points will be found in the book for all classes of horses. Turn a horse from the right to the left and if he is weak in the back he will step wide out. Turn a horse short around, if he is stringhalted he will jerk his legs up.

The deafer a horse is the straighter he 
sticks up his ears and the less he works them. If a mean disposition, a horse will work his ears back and forward and under his upper eyelid he will show the white of his eye.

Mooneyed or Weakeyed Hurse.-The weaker the eye the straighter the ear, and the ear will tip over the strongest eye. The curl in the forehead should be above straight across between the eyes, the higher the curl the better good point for strong eye.

A driving horse should have a !ong slim neck and thin in the throatlatch, high head and high withers. The older they get the lower they will get in the back. For a ewe-necked horse or colt to grow them a good neck, pull up on the neck as they fatten.

Look for Pollevil or Fistula. Pollevil comes on top of the head, fistula comes on the withers. Look for scars where they have been. Look for rupture, it comes on the side of the belly or close to the navel. 


\section{THE HORSE}

Thick Wind, Bull Heaver or Common Heaver.-To test a horse with bad wind punch him three or four times behind the front leg; if bis wind is bad he will make a rattling noise that isn't natural. There is a hole in the throttle you can get your two fingers in, push up and squeeze and if he is wind broken or heavy he will cough. A wide open nostrils and the red shows lower in the nostril for heavy or bad wind. The nostril holes drawn close together and wrinkled shows they have been too hot. The nostrils straight up and down, wide and smooth between them for good wind. The nostrils thin and the butt of the ear thin for good wind.

\section{FOR HIGH BRED TROTTING HORSE}

The plainer the rings show below the pastern joints, the better are the points for high breeding. If the wart on the pastern joint is small and pointed they are half bred trotters, and when the wart above the knee is round and points up it shows trotting and draft both. This kind of a horse is more of a general purpose horse and is handy on his feet. 


\section{A HORSE THAT IS ELIGIBLE TO A REGIS- TER}

When there is no wart on the pastern joints, but flat and smooth and the shorter the hair the better on the pastern joints. The splint bone shows plain and the wart above small and narrow. If there is just skin stretched over the bone below the hind knee, it shows high breeding on a colt or old horse. The sharper the bone at the neck and the sharper the bone between the ears the higher they are bred young or old. The ring shows plainly below the pastern joints.

\section{DRAFT BROOD MARE}

Wide forehead, wide between the eyes and a good sized eye, wide between the ears, a heavy neck and not too full in the throatlatch, wide between the points of shoulders that would give a good heavy breast, that would denote strength, a good heavy bone from the breast to the hoof and a heavy knee, a good sized foot and round, heavy in the withers, heavy and short in the back and wide in the kidneys, wide in 
the hips and full, low in the flank, heavy in the stifle, wider in front than behind, a flat bone and a heavy knee, a good heavy pastern joint and not too much fiesh in front, short from the knee to the pastern joint and short from the pastern joints to the hoof, a heavy tail bone and heavy mane and tail. These are breeding points for draft. Look for these points in pick: ing a draft colt.

\section{A DRAFT STALLION}

First see that he has not a roman nose nor dish face. A good wide mouth and wide above the nostrils. See that the bone above the eye is not too heavy. 'That is one of the points for rough breeding. Not too large an ear and not set too much to the side of the head. A horse should be wide between the eyes. The eye not too small nor too dark. The hazel eye is a good eye, not too heavy around the heart nor too thick in the throatlatch. Heavy in the shoulders and wide in the breast. A heavy bone from the shoulder to the foot. Round foot and not too flat; not too high in the withers; short in the back; wide 
across the kidneys; wide in the hips and full down to the tail bone; a heavy stifle and a low flank; a round rib and not too flat; not too crooked in the hind leg. The leader on the hock to run up heavy. Short from the pastern joint to the knee; short from the pastern joint to the hoof, with a good heavy flat knee, not too much flesh in front of the pastern joint.

\section{HOW TO TELL THE AGE OF A HORSE}

As a horse grows older the tips of the ears lean forward. Look for a crease in the lower eyelid that comes at nine years of age and one comes every year after that. 'The chin is sharp when a horse is young and as they grow older the chin gets flater. The older the horse the sharper the jaw bone.

\section{POINTS FOR GOOD WIND ON A TRACK HORSE OR ON ANY FORSE}

The open part of the ear at the bottom, take your two fingers and put the ear between and the thinner the better. The nostrils straight up and close together is a good point. The wider the nostrils apart 
at the bottom and the smoother between, the better are the points. The outside of the nostrils, put between your fingers and the thinner and more solid the better.

\section{BAD WIND ON ANY HORSE}

The closer the nostrils are together and the thicker and softer the outside of the nostril is a sign that they have been too hot. Put the open part of the ear between the fingers and if it is thick, also if the crease below the ear at the neck, when you push in on it is soft and deep are good points for bad wind. If there are lumps under the throat and at the butt of the ear it is a sign that they make a noise when they are moved. When the nostrils turn out and open at the top and red on the inside are good points for a heaver.

Gravel or Irritation. of the Bladder.-This is a disease that, in some respects, resembles gravel. When the urine drops into the bladder they feel like they want to urinate, then they will squat.

Give about a teaspoonful of baking soda or bicarbonate of soda. Give three times 
a day for a week, then give nitrate of potash in teaspoonful doses twice a day for a week, then give soda again.

To Remove Warts.--If they are very large it is best to cut them out. If they are bloody warts, sprinkle sulphate of zinc or white vitriol on them. If the warts are hard, get some nitric acid, make a small swab and put the acid on with it. This will burn them off.

Thrush in Horses,-Take calomel and put into the crack of the hoof, and then put cotton in to hold the calomel.

Another remedy is to take blue vitriol and pulverize it, and put it on the bottom of the foot and in the craks. Mix lard with it and spread it all around the foot.

Another good remedy is soft soap and coal oil. Make it into a paste and apply with a rag wrapped on a stick. Make it thick enough to work good.

Levered Leg.-Caused by a strain or a bruise.

Cure.-Take clay and salt and mix together, about one-fifth salt; make a thin 


\section{THE HORSE}

batter and bind on, and if this fails, blister.

If there are any sores they should be healed first.

A horse with a fleshy leg is apt to have a fevered leg.

In case of colic and the horse is loose in the bowels, give him something to bind him up. If you have got no medicine for this purpose, give one quart of strong, hot coffee. Repeat in one half hour if needed.

A quart of sage tea with a spoonful of turpentine is also good. Don't forget to use plenty of hot water on the back until the horse gets relief.

Big Head.-Comes between the eye and nose, sometimes both sides are affected, raises up in a lump. Weak eyes will some. times cause a lump to raise below the eye.

Cure.-Take May-apple ront and boil until thick and strain and bathe. Corrosive liniment if other should fail.

Proud Flesh-This comes on an old sore and swells up and looks red or blood colored. Apply burnt alum. 


\section{THE HORSE}

To Find if a Horse is Lame in the Foot.Take up the foot and tap on it with a hammer, and when you strike the place the horse will flinch.

To Make a Horse Look Sleek.---Rub with a rag with a little coal oil on it.

To Grow Hair on an Old Sore.-Use sweet oil or fresh butter without salt.

Chills.-When a horse has chills it is generally the forerunner of some other disease. Give about five times as much quinine as a person takes in one ounce of water.

Another good remedy for chills is a pint of calamus tea.

To Grow Hair on Mane or Tail.--Take. a tablespoonful of coal oil in a gallon of water and wash once a day.

Poison.-To tell whether a horse is poisoned, pour a little water on his back and rub. If he is poisoned it will lather like soap suds. Horse has same symptoms of lung fever:

Cure.-Give the horse a pint of sweet 


\section{THE HORSE}

oil or lard and six eggs broken into it, and then move the bowels by giving a tablespoonful of aloes dissolved in water, or a pound of salts.

Corns.-They are usually the result of bad shoeing.

Use sugar of antimony, as for hoof bound.

Coffin Joint Strain.--The hurse should not be wrrked while doctoring.

The majority of cases are incurable.

Bathe with turpentine and coal oil, equal parts.

Side Bones.-They come in the side of the hoof and grow about the hoof. They sometimes lame a horse and sometimes go away without hurtıng a horse.

Remedy.-Cut the hair off close and use spavin remedy freely to stop the growth.

Ring Bone.-Cut off the hair and use spavin remedy three times - twice the first day and once the second day.

Scratches and Grease Heel.-Use hot wood ashes. Take on a shovel and throw un. Also take one part calomel and three 
parts lard. Apply every day until cured.

Laxative Drench-Physic.--

Barbadoes aloes, 3 to 5 drachms.

Castor oil, 3 to $6 \mathrm{oz}$.

Carbonate of soda, 2 drachms.

Mint water, $8 \mathrm{oz}$.

Mix by dissolving the aloes in the mint water, by the aid of heat, and then adding the other ingredients.

For Pinkeye Distemper in Horses.--Bind the legs with dry mustard, ground, and bound on with cloths; also sprinkle on back from withers to kidneys. Take a grain sack and place in it a bucket of boiling water and put the horse's head or nose in the mouth of the sack so that he will get the steam.

Shock for Horses or Cattle.-For all ailments requiring quick relief, or for nervous or spinal trouble, for spasmodic colic, lung fever or milk fever in cows, or any kind of founder, for cow or horse: Take one teaspoonful of gunpowder and place it in a tablespoon and hold it six inches below the nose and light with match or paper fuse. 


\section{THE HORSE}

Rheumatism.-

Iodide of potassia, I oz.

Water, I pt.

1 ablespoonful three times a day.

Mexican Mustang Liniment.-Petroleum oil, olive oil and carbonate of ammonia, equal parts; mix.

For Bad Cuts or Kicks on Horses, Causing Inflammation or Great Pain.--Take a bucketful of wood ashes and put two gals. of boiling water over them and strain, and add corn meal to make a mush of it and bind on with cloths while hot and keep cleaning them and keep them hot for six hours, or until relieved.

Stringhalt Horse Remedy.--Camphor and butter, equal parts, and as much alcohol as camphor and butter together, and mix. Rub on twice a day for two days, and in week repeat the dose.

For Wire Cut or Kick on Horse.--Burnt alum and calomel, equal parts. Put calomel in after alum is burned. Sprinkle on cut. 


\section{THE HORSE}

Ointment for Horse.--4 oz. resin, $4 \mathrm{oz}$. beeswax, 8 oz. lard, 2 oz. honey. Mix slowly and gently bring to a boil; then add less than one pint spirits of turpentine; then remove and stir till cool. Unsurpassed for horseflesh.

To Stop Bleeding from a Wound.-Make an application of dry manure, and it will stop the bleeding of a wound at once.

An Easy Cure for Glanders.--One oz. rock alum, one oz. white vitriol; powder these well and put them into a pint of warm vinegar, and syringe about one pint up the nostrils each day.

Recipe for Heaves in Horse.--Use wild morning glory seed, one tablespoonful twice a day for five days, then wait four or hve days and give the same for four or five days more. This is a sure cure.

Sweeney on a Horse.-Take turpentine and coal oil, half and half, rub well with the hand until it gets warm, then rub the medicine on until the hair is wet. Use morning and evening and again the following morning, making three treatments in 


\section{THE HORSE}

all. This remedy is used for Hip, Bone, Muscle and Breast Sweeney.

Thoroughpin on Horse.- Use same remedy as used for Sweeney. Put on until the skin raises and yellow water oozes out. This will stop the growth, and if they are not too bad, will cure them.

Remedy for Sore Shoulder on a Horse.Alcohol, turpentine and fish oil, equal parts; mix well and rub on shoulder.

\section{VALUABLE RECIPES}

No. I. For the Cure of Pollevil and Fistula.-Twenty-five cents worth of Caustic and Calomel, equal parts-put the two ingreuients in a bottle with an ounce of water; using a syringe to apply it in the opening place, or places of the diseased parts.

No. 2. For the Cure of a Horse After Hard Driving, when the leaders become sore and affected.-Take one quart of Gasoline 
to a dime's worth of Gum Camphor; mix and apply on the leaders and pastern joints, and on the bottom of the foot. In using Gasoline be careful, in all cases, to keep away from fire and the light of a candle-to avoid accidents.

For Neuralgia-The above preparation is equally good. Apply on the pastern joints, rubbing on good.

No. 3. For the Cure of a Horse Unable to Make Water.-Make a quart of Cuckle Burr Tea. Get a quart of the burrs and use water sufficient to make one quart of the tea. Put the preparation in a bottle and drench the animal well.

No. 4. Another Recipe for the Same Purpose.--Buchu, one ounce, and Spirits Nitre, one ounce: mix together, with one-fourth of a pint of warm water; put in a bottle and drench.

No. 5. Physic for Horse or Cono.-Take Burdock Root and make one-half gallon tea; put in one pint of salt and let dissolve. May be used with good effect on either cow or horse. 
No. 6. Another Physic for Horse or Cow. Take a pint and a half of melted Lard and the same quantity of Molasses, and, after warming sufficiently to make the ingredients mix well together, drench the animal affected. In bad cases, use the above preparation; if the case is not so bad, use less.

No. 7. For a Sore Shoulder or Neck on a Horse.-Use Arnica; applying frequently.

No. 8. To Make a Liniment for the Cure of a Swelling or Bruise.-Take one pint of Cider Vinegar, one pint of Turpentine, and the white of two eggs; mix together and let stand one-half a day, when it will be ready for use. Apply frequently to the swelling or part affected.

No. 9. For a Horse Having Fits.--Give the horse a tablespoonful of Gympson Seed every day for five days; then wait ten days, when you should give the same amount for five days longer. If you can find out about the time the fits come on, use the medicine six days before the fits come on. This will afford great relief, if it does not entirely cure. 
No. Iо. For the Cure of a Bloated Cow.-Take hold of the tongue and pull briskly back and forward until it makes her belch.

No. I I. To Make a Horse Sleek and Clean Off the Dandruff or Dust.--Take a horse brush, wet it and rub the curry comb over it; then $r u b$ the horse with the brush. This will clean the horse and make him look clean and sleek, if properly applied once a day for three or four days.

No. 12. How to Control a Horse and Hitch Him Up.--Put fifteen drops of Sweet Annis under the upper lip and in the nostrils. If the horse is a little wild, use a few more drops. Let him stand fifteen or twenty minutes and then hitch up.

No. 13. To Prevent a Cow From Sucking Herself.--Scrape an Indian turnip, put in flour and water, and make a paste. Make it strong with the turnip, then spread upon the udders.

No. 14. Another remedy is to take Cayenne Pepper and make a strong paste with flour and water and apply as above. 
THE HORSE

No. I5. To Prevent a Horse From Biting. --Throw Cayenne Pepper in his mouth. This, if used every time a horse attempts to bite you will soon be relieved from this trouble.

Nu. I6. Use Cocaine in a horse's eyes to clean off the scum when moon-eyed or hurt. Blow six drops of the preparation in the eye with a quill; get five cents worth of Cocaine powder and put in an ounce vial with the water. Use twice a day for two days and theı once a day for three days.

No. 17. Use Cocaine--eighteen drops-in the frog of the font of a horse, which will numb the pain and make the horse walk better for the time being.

No. 18. Spavin Recipe For Horse.--A wooden bucketful of Honeysuckle roots, boiled down in twenty gallons of water to less than three pints; then strain and put lard in sufficient to make a paste thick enough to spread on. This will relieve and cure both Spavin and Ringbone; put on according to the size of the Spavin, 


\section{THE HORSE}

twelve times, if large; less, if small; then wait four or five days, and apply again, if not relieved, four or five days. This absorbs the bone, making it come out through the skin.

No. I9. To Cure Mange On a Horse.-This is a skin disease and may be cured by the use of two ounces of Creolene in two gallons of water, and wash twice a day intil relief is secured.

No. 20. Another Remedy for the Cure of Mange.--Take a quart of Rainwater and Salt and Tar Soap (using salt sufficient to make a strong solution, or lather); apply on one-fourth of a horse at a time; then give time to let dry, when apply again to other parts in like proportion, letting dry again-then apply in similiar manner until the animal has been entirely gone over. This preparation is so strong that horses will not endure being gone all over at one time. This preparation may have to be used several times before relief is affordec.

No. 24. How to Know a Dummy Horse. --Before you buy a horse, tramp from the 


\section{THE HORSE}

pastern joint down to the hoof. The duller he is in the feet the slower he will pick them up. A regular "dummy" won't pick up his feet at all. You may peel the skin off and yet he will not move.

No. 25. In feeding Cattle, frequently they are physiced too much. 'To prevent this, a tablespoonful of Alum, put in a little meal in a pan, and fed the animal affected twice a day for the first day and once the next day until relief is afforded.

No. 23. How to Grow Hair on a Horse having had a sore or callous, which has been healed up.--Take a pint of Dead Honey Bees, burn them to ashes, and then put in sufficient Sweet Oil to make a paste. Apply every day until the hair a ppears. This will make the hair grow if anything will.

No. 24. To Treat a Wire Cut on a Horse or Cow.--Carbolic Acid, a teaspoonful to a quart of water. To take more, a tablespoonful to a half gallon of water. Use three times a day on the part or parts injured. A syringe will be found useful in applying it. If a syringe is not at hand, 
make one from an alder, similiar to those used by the boys for "squirt guns."

\section{SPASMODIC COLIC RECIPES}

Symptoms.-The horse lies down and gets up often, rolls and tumbles about, looks at his flanks; his ears and legs are often cold.

No. 25. Rub three ounces of Turpentine, half behind the front leg, and the other half behind under the flank on the veins; use the other side the same way; also rub the substance under the lip and in the nostrils.

No. 26. Take a Dog Button and pulverize it: put in a half pint of warm water, and then drench the animal with it.

No. 27. Take Laudanum, one ounce; Sulphuric Ether, one ounce; half pint water (milk warm); drench, and if not better in half an hour, bleed through the nostrils and repeat the dose.

No. 28. Take piece the size of the end of your thumb from the wart on the horse's leg, cut it up fine and put in a pint of whiskey and drench. 
No. 29. Calomel, one-half drachm; Opium, ten grains; Ginger, three drachms; Rhubarb, three drachms; make into one pill, and give at one dose. Repeat in two hours if not relieved.

Ropes and Bridles for Control of a Horse-For Kicking, Leading, Rearing Jumping and

\section{Running Away}

Make a loop that will not slip seven or eight inches long on end of rope. Slip over under jaw, bring from right, over neck to left side of head, then under lip to right side, then upward across top of head behind ears, then down on left side through the loop. If you want to change to other side just reverse. Can be used single or double.

For Rearing.-Tie ring in end of rope, stick other end of rope through ring to form a loop over under jaw; when they rear, loop draws tight; bring back between front limbs to girth and fasten. Can be used for ridingor driving.

To Keep Most of Horses Quiet While Shoe- 
ing.-Use rope with ring in end; lay ring on top of head behind the ears, downward, on right side, under upper lip, then upward on left side; through ring, and pull down.

For Control of Wild Horse in Stable.-Use. rope with ring, get above the horse; form loop through ring and slip over horse's head; draw easily, then come down; keep hold of rope; open door and let horse out. If he runs or fights choke him. After he gets down, use bridle as in No. 30.

For Runaway Single Horses.-Use rope with ring and form loop in rope; put loop over upper lip, upward between ears; back through harness ring, and then back to buggy. Tie to nose piece and between ears to keep from slipping.

Colt Bridle.-Make loop in end of I 5 -foot rope long enough to go around colt's neck. bring rope forward on right side through mouth; then back on left side through loop that goes around neck. Iull sideways until colt comes to you, then pat him on the nose to get control of him.

For Horses that Scare and Run Away.- 
Use rope with small ring in end, loop around under jaw, bring end of rope through outside bridle ring on near horse, then across nose and through other bridle ring, through inside hame ring of off horse and back to lines. If used on two horses, use same as before. This is intended to be used on horses that have habit of running away.

\section{Easier Way To Rope Runaway Horse.-} Tie rope to inside bridle ring, bring under jaw through outside ring across nose through inside bridle ring, then back through inside hame ring to lines. Tie rope to outside bridle ring, pass around under lower jaw and through inside bridle ring, then through ring in buggy pole, or wagon tongue, back to buggy or wagon.

To Throw a Horse.-First, put a surcingle around the horse, then fasten a ring on top of horse's back to the surcingle. Second, put a crupper on the horse and fasten the end to ring in surcingle; then put a rope around the horse's neck like you were going to tie it, then forward on left side through the mouth back on the right side through 
the loop; then through the ring on top of horse's back; then tie left leg up with strap. After leg is tied one man may push his head to the right and another man pull the rope and the horse will fall over on left side and will not be able to get up until strap is unbuckled.

For a Horse To Break Himself from Kicking.- Put the harness on a horse with the exception of lines, and tie the tugs in rings in breeching. Cross holdback straps under hor se and fasten to shaft carriers, to keep horse from kicking harness off. Use double rope long enough to put under upper lip and then up over head between the ears and fasten to head stall of bridle; then back through each ring on back band; then back under tail and draw up and tie tight. Draw rope together and tie about six inches above to keep rope from slipping off. 'Take a grain sack with four or five ears of corn and tie to horse's tail or crupper, then turn out in a lot and let him go until he breaks himself.

To Work a Kicking Horse Single.-Take two ropes, tie one ena of each to bridle bit 
rings, bring upward over horse's head between the ears, then back through rings on back band and through crupper and tie on each side of horse to shafts. Fasten ropes in top of horse's head to headstall of bridle to keep them from slipping off.

To Break a Horse From Halter Pulling.Buckle a strap with a ring on it around each hind leg below the pastern joint; double a rope and tie each end into rings on hind feet; then pass through a rope or to hold ropes up; then between fore legs and through halter ring and tie to hitching post or manger and if the horse pulls he will pull his hind feet from under him.

\section{To Break a Horse From Kicking to Plow} or Harrow. - Buckle a ring to each hind leg below the pastern joint and one to each fore leg above the knee; take two ropes, tie one to each ring on hind legs and pass one through each ring on fore legs, and fasten to each side of bridle bit, and if he kicks it will pull his fore feet from under him. 


\section{THE HORSE}

No. 30 To Drop a Horse on His Front Knees.-Put a rope around the body, and put two rings six inches apart, and buckle $t$ wo rings on each front leg below the pastern joint in front; tie the rope to the left ring on the left leg, then through the ring on the left side; then down through the ring on the right foot, then through the ring on the right side, and then back to the line. When he gets to kicking or running you can throw him on his front knees. Pad his knees with an old piece of carpet or something else at easy commani to keep from hurting him.

No. 3i. A Horse That Is a Halter Puller.--Tie a ring in the end of a rope and around the body and stick the end of the rope through the ring, then take the rope between the front legs, then through the halter ring and tie it to the manger. This can be used for a balker by tying to the end of the wagon tongue. When he pulls back it will draw on his body and make him step up. 


\section{THE HORSE}

No. 32. To Harness a Mean Colt or Mule.-Take a rope and double it and make the rope even, then tie a knot in double end, one foot and a half from the double end, then lay it across the back then buckle two rings below the pastern joints, on the hind leg below the pastern joint, then buckle the left front foot up; then tie the rope in the left ring in the hind foot; now let the front foot down and buckle the right front foot up, and then fasten the rope to the ring in the right hind leg, and tie another short rope in front of the hind legs; the rope should go on both sides of the neck and hind leg to keep him from kicking sideways. After getting the beast harnessed, take off the little rope and leave the other rope on until the animal will stand to be harnessed.

No. 33. To Stop a Horse Jumping.Buckle four rings around each pastern joint; tie a rope around the body with two rings six inches apart; then take a rope and in a ring on the front leg and then through the ring under the horse to the ring on the 
hind font. Perform the same operation on the right side, then tighten the rope and lead the animal around a little before letting him go.

No. 34. A Balking Horse.-Buckle two rings fast to the hip strap each of them one foot long; double the rope and put under the tail through each ring and fasten to the outside hame ring of the balking horse and then take it across the true horse's back to the outside ham ring. Jush the true horse back and pull the balker up and tighten the rope and start the true horse. This will move him.

No. 35. Spinning a Mean Horse.-T ie a rope to his bridle bit: then tie a loop in his tail; stick the rope throing the loop, then pull on the rope or tie his head to his tail, if he can't be controlled otherwise.

No. 36. Another Halter Puller.-Take a rope twenty feet long and double it, and put through the halter ring; then back around both hind feet below the pastern joints between the front legs. Then pass the rope under the ropes and over the neck 


\section{THE HORSE}

between the breast and halter ring, so that if the halter would tear the rope would hold him; afterwards to the manger or post, whichever is most convenient; then watch the animal when pulling that he don't hurt himself unnecessarily.

No. 37. To Teach a Horse Tricks.-Teaching a horse to talk by nodding or shaking his head. When you want a horse to shake his head stand by the side of him at the shoulder and prod him with a pin where the collar rubs the hair off the mane. Prod him until he shakes his head, then rub the place where you stuck the pin; then stick him again, when he will shake his head on asking him about moldy corn or oats, whether he likes to work. When again you prod hım he will invariably shake his head. This is the way to learn him.

No. 38. To Make a Horse Nod His Head. -Step back to where the buggy harness works and prod him with a pin; then rub the place and stick him again until he nods, and then ask him whether he wants good oats or corn; afterwards step forward 
again and prod him again until he shakes his head; then step back and prod him until he nods his head again; after which step forward and hold your hand up until he shakes his head and then step back and hold your hand up until he nods. This is the way to teach him to do these tricks.

No. 39. The Trick to Teach a Horse to Stand on his Hind Feet.--Prod him luw down on the breast with a pin, pull up on the strap of the bridle at the same time; keep on doing this until he stands on his hind feet.

No. 40. To Teach a Horse to ShakeHands --Prod him on the inside of the right front knee, taking hold of his foot at the same time; then, by proding or sticking him again and taking hold of the foot at the same time, you learn him to hand up his foot when you tell him to "shake hands."

No 41. The Trick to Teach a Horse to Lay Down.--Put a pin in a little short whip, and with this hit him on the back part of the left knee, holding him with the bridle at the same time. Do this until you 


\section{THE HORSE}

get him to lay down a few times, then take the pin out of the whip, after which tap him with the end of the whip at the same place. This will teach him to lay down, as you want hin to do.

No. 42. The Trick to Drive a Horse Without Lines.-To stop a horse, hold the whip straight up; if you want to start him, lay the whip down straight with the horse. When you want him to turn to the left, turn your whip in that direction. If you want him to go in a circle keep your whip close to his body. If you want him to go to the right, turn your whip in that direction; also, if you want him to turn in a circle to the right, hold the whip close to the body on the right side; if yo u want the horse to stop, bring the whip to the center of his body; then by raising the whip up in a straight position, the horse will stop. To teach these tricks quickly, take a bridle without blinds, put on a severe bit, then pulling on the lines give him a pretty severe surge. This will teach the horse to go in whatever direction you may indicate by your whip. Use him this way with the 
lines, after which, if you desire, you may use him without the lines by the motion of the whip alone.

No. 43. How to Tell the Weakest Eye in a Horse, when sitting in the rig or vehicle behind him. - The ear will stand the straighter up on the side of the weaker eye. On the side of the head of the good eye, the end of the ear will incline to tip over. Watch this and you will discover the weak er eye of the horse.

No. 44. The better the wind of a hors $\mathrm{e}$ the straighter the nostril. To try a horse's wind, take the thumb and finger of the left hand and squeeze behind the throttle on the throat, putting your fingers in the crease, push up and squeeze. This will make a horse cough if he is troubled with heaves or bad wind.

No. 45. How to Fix a Horse to File His Teeth.-Take a plow clevis and put in his mouth, then take a file with a long handle and file the sharp edge off the jaw teeth. File both sides the same way.

No. 46. If you want to kill lice on your 
chickens in the coop or other places, take a watering can and make a strong salt water preparation and sprinkle it around the coop or other places where the chickens congregate.

Note.-Don't forget to keep brimstone on hand. Look up the recipe in this pamphlet. It will be proper in bad cases to use a greater quantity than stated-four table spoonfuls may be necessary in some bad cases.

Horse That is Bound Up.---How to tell: They will turn their upper lips up, and will he pretty still. Sometimes, when not so bad and it is pretty hard to tell just what is the matter with them, they will get up and go to eating; they will paw and lie down if not too bad; if they are, give them physic.

Raw Flaxseed Oil, I pt.

Turpentine, I tablespoonful.

Punchered Sore on a Horse.-Tỉe flesh turns out and louks red. Get pulverized Blue Vitriol and sprinkle it on. The best way to use it is to take a baking powder 
can and punch holes in the lid from the inside out. This can be used for proud flesh.

To Fatten a Horse.-Get Red Pacoon root, and take roots enough to make three times the length of your finger, put in a pint of Cider Vinegar, give a tablespoonful twice a day in the feed. Fill second time with Vinegar and the third time with roots and Vinegar both.

A Remedy For a Weak or Mooneyed Horse. This is an extra good remedy.--One pint of Linseed Oil, two ounces Gum Camphor, one-half ounce Spirits of Ether, one teaspoonful of Salt, twelve drops Cocane. Take a feather and put in the eye twice a day.

Remedy for a Weakeyed Horse.-Five cents worth of Cocane, if in powder put in water, put in an ounce bottle or if it is in liquid, give six drops twice a day for either one until the eye clears up.

Another Remedy.-Holland Oil, in ten cent bottles, drop around the eye and a little at the corner.

To Stop Blood from a Cut of any Kind on 


\section{THE HORSE}

a Horse.-Put clay or dirt right on the cut and bind it up.

Remedy for Wire Cuts or Sore Shoulder on a Horse.--Three pints raw Linseed Oil, one ounce Oil of Organum, one ounce Oil of Cedar, one ounce Oil of Hemlock, one ounce Oil of Sassafras, two and one-half ounces pulverized Gum Camphor. F'ut in a new stone jug, let stand thirty-six hours. Shake the jug frequently.

Remedy for Cough for a Horse.-Twofifths of Ginger of amount wanted, twofifths Slacked Lime, one-fifth Ashes, give one tablespoonful twice a day. This is as good a cough remedy as you can use.

A Remedy for Horse Colic. One-half ounce of Jamaica Ginger, one-half ounce of Laudanum, one ounce nitre. Give dose every thirty minutes.

Col. Horn Wants to See the Man that can Furnish a Better Remedy for Cure of Fistula or Pollevil.--One ounce pulverized Spanish Fly, one ounce Blue Stone, Lard to make salve, apply salve to swelling. If mattered cut open and put on inside. 
Remedy for Fistula on Horse.-Carbolic acid, put cotton on end of a stick and swab out sore, then put medicine in.

Another Remedy for Fistula.--One pint pure Cider Vinegar, one pint Turpentine, one ounce Nitric Acid, a five cent cake of Castile soaf.

Also for Fistula.-Get Amber Oil; put cotton on the end of a stick and put medicine in sore to eat pipes out. Take a little salt water and wash out good before applying the second time.

For Fistula on Horse.-One vunce Chloride of Zinc; put in sore twice a day then wait a day. After using torst time weaken a little.

Another Remedy for Ftstula on Horse.To be used before it breaks. As soon as it swells use recipe as it says Corrosive Liniment. One ounce Corrosive Sublimate, one ounce Gum Camphor, one-half pint Turpentine. I'ut this on heavy the first thing in the morning and let stand until noon, then take a cup and pour on about one gallon of water (in cold weather use water a little warm). Repeat this until 
you have used three doses of liniment, making each dose about iwelve hours apart, and the water should te used between the doses. Use the water until the fever has disappeared and then you will have control of the disease.

Fistula on Horse.-Use Ashes of burnt corn cobs after the sore has broken open. Then fill the pipes with these ashes which will rot them so that you can pull them out.

Fistula on Horse.-Take a small sack and fill with salt and put sack over the sore, then pour water on the sack and let it run into the sore.

Fistula or Pollevil on Horse.-Pulverized Blue Vitriol, put in a baking powder can with small holes $\ln$ the lid from the inside out and sprinkle it on. Put Lard on below the sore for all these remedies to keep the medicine from taking the hair off. Take a stick and wrap a rag around it and wash out the sore so that you will not need to use your hands. If any of the prescriptions are not enough to cure, use more. 
54

\section{THE HORSE}

For Distemper, Fistula and Pollevil and also a Bruised Shoulder, or where there is likely to be Puss.-Press down with finger and if it stays down and parts it is ready to open and when it pops up right away leave it a few days. If you have a bruised shoulder on a horse take Turpentine and Coal Oil, equal parts. This draws it from inside out to the place of letting it gather.

Recipes to close Heaves on a Horse for Trading.-White Antimony, about half what your thumb nail would hold for a dose. Put back on the tongue and drive.

Calomel about what you can put on the end of a pen knife and put back on the tongue and drive. Use these remedies according to how bad the heaves are.

A Remedy for a Bloated Cow.-Pour cold water on the back.

Another Remedy. - Pull the tongue back and forward to make them belch.

To Keep a Cow from Jumping.-Cut the upper eye winkers off close.

To keep a Mule from Jumping.-Put a 


\section{THE HORSE}

hog ring in the top of each ear and tie them together.

Texas Itch on a Horse.--Sheep dip, and wet the skin, the next morning, wash off. Then put on again, then wash off again, it will take three times to kill the disease in this manner.

To Kill Lice on Horses, Cattle, or Hogs.-One pint of Lard, two tablespoonsful of Coal Oil. Commence above the eyes and put clear to the tail, rubbing along the back-bone, about four inches wide.

A horse that is sick, the more fever he has, the less water he will drink.

A horse that is poisoned is hard to doctor, because they have no gall.

A Horse Powder.--

Salt; 2 qts.

Linseed meal, 2 qts.

Wood ashes, 2 qts.

Fine tobacco, 2 gts.

Slacked lime, 2 qts.

Sulphur, I lb.

Copperas, $\frac{1}{2} \mathrm{lb}$.

Alum, $\frac{1}{4} \mathrm{lb}$

Sift and mix together. 


\section{THE HORSE}

Give tablespoonful to horses and cattle; a teaspoonful to an old hog, and not so much to younger hogs according to age. For chickens, two tablespoonfuls to one gallon of feed.

\section{Sore Shoulder.-}

For a horse with a sore shoulder take I pound Raisens, add I quart water, boil until soft and strain the juice off. Add one cup of Lard to this juice and boil until it becomes a thick salve. Then it is ready for use.

Remedy for a Horse with Heaves.-Cider Vinegar and Coal (Oil, equal parts, onehalf cupful at a dose, throw back on the tongue with a syringe. Use two or three timies a day, according to disease.

Heave Remedy.-Cream of Tartar, one tablespoonful twice a day for two weeks. The third week reduce the dose to one teaspoonful twice a day.

When Making a Long Drive.--When y ou want to make a long drive, give your horse one ear of corn less for the meal before you drive. And let him walk for a hundred 
yards or so when ever you think it necessary. And as you go along, and if your horse physics, slack up and let the horse walk a while; if you do, your horse will come out in good shape at the end of the journey, but if you don't slack up you may have a sick horse.

An Excelent Remedy to Draw the Poison from the Wound of a Rusty Nail or any Rusty Piece of Iron, on a Horse.--Drop sugar on a few live coals and cover it with something that has a small hole in the top, so the smoke can not spread out so much. After you have done this hold the wound close over the smoke for a few minutes. This will kill the pain, and draw the poison out, then the wound will begin to heal. Use for a wire cut where there is lots of pain.

A Horse Subject to Colic.-Tie a little piece of plug tobacco on the bridle bit, and work the horse. This will keep off the colic.

The cause of a Sick Horse a great many times.--The horse has been fed too much, when it was not working. 'You should not 
58

\section{THE HORSE}

give as much feed when the horse is not working.

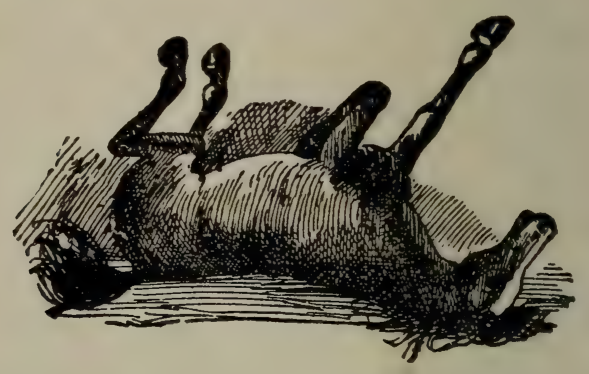

A Remedy for Horse Colic.--One tablespoonful of Turpentine, and one ounce of Whiskey, repeat in one-half hour, if not relieved.

For Founder on Horse or Cow.--Give one teacupful of yeast, and if this does not relieve the horse or cow, give another teacupful in one-half hour. If this is not enough give a dose in three or four houis.

For Kidney Trouble on a Horse.--Get Sulphur and Salt Peter of equal parts. And when you see the horse is off in the kidneys, give a teaspoonful, twice a day for a week, then, give one teaspoonful every day, until you think the horse is relieved. This is also a good blood remedy. 
How a fifteen year old Boy can pick a High Bred Horse or Colt. - Short hair on the pastern joints. No wart on the pastern joint, but flat and smooth. The wart above the knee long and narrow. The sharper the neck bone and the sharper the bone between the ears the better. The skin stretch ed tight over the bone, below the hind knee so the leaders show plainly. The ring below the pastern joint shows plain. This kind of a horse or colt is eligible to a register.

Foot Evil in the Frog of a Horses Foot.Get powdered blue vitriol and thin with hot lard. Clean the foot out good. Then put the medicine in hot, and after this is done put cotton in to keep the medicine in.

For a Lump of any Kind on a Horse.--Rub the lump crosswise. This will reduce the lump quicker than any other way.

For Astera.-Use Sulphur and Salt Peter to keep Astera off. A horse will fall very quick with this disease sometimes Use this remedy occasionally. It is good for the blood and kidneys and will keep the disease off. 




\section{CATTLE}

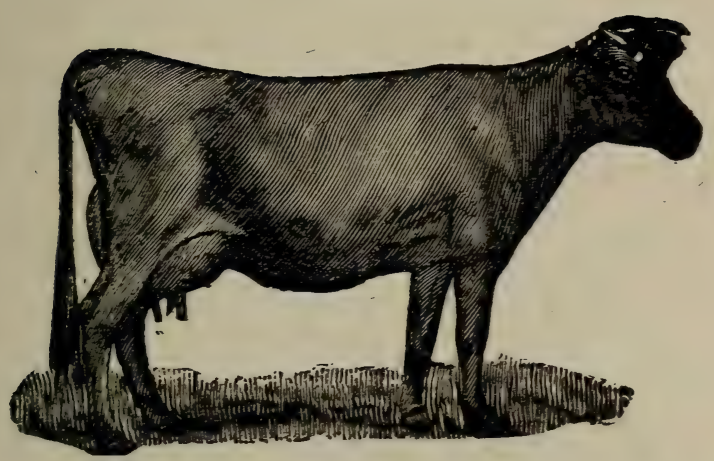

A Fullblood Jersey Cow.-A Jersey cow comes off short below the eye and the plainer it shows the more Jersey. Wide between the eyes, the front bone is higher than the back bone hehind the coupling. The bone must show plainly on the Jersey, Alderney and also on the Guernsey. Either of the breeds could be fullblooded and not have a black switch but the black switch is a good point for good breeding. The Alderney is black and the Guernsey is yellow and white and sometimes a black spot but this does not belong to this breed The Alderney crossed with the Jersey is brown around the eyes and nose, brown on the shoulders and brown in the flank. The 
Aberdeen Angus are a beef cattle and when they are crossed with the Jersey, which they do sometimes, this makes the Jerseys a larger cattle. They show too much black from head to breast and in the flank. This shows the cross. Be careful and watch these points. If you don't have to pay for that pedigree you can make that cross yourself.

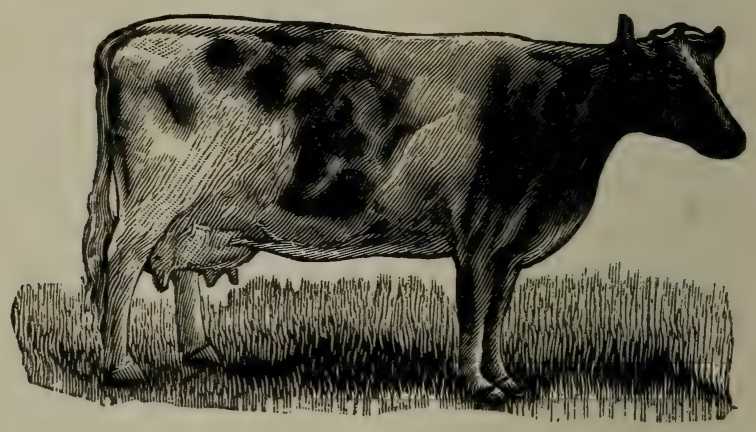

The Fullblood Holstein Cow.-The Holstein has a white spot on the forehead, black nose and neck, white across the shoulders, white across the kidneys and some white ou the limbs. 'There is not as much white on the Holstein now because they are crossed with the Aberdeen Angus and show more black than white. The Holstein crossed with the Aberdeen Angus makes better beef cattle. 


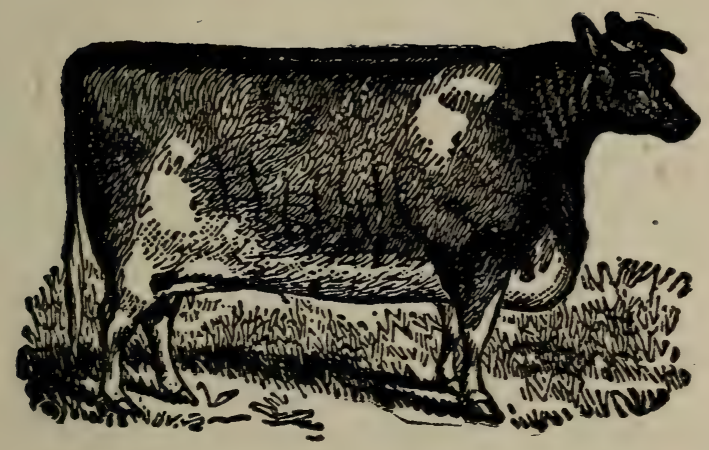

Roan Durham Heifer. - Look for the same points for cows or heifers as the book says for high breeding of any breed.

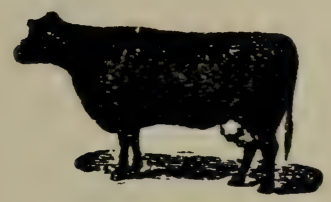

The Fullblood Poll Durham Cow.-The Poll Durham are red and they make a good beef cattle. If you look at the good milk points as the book says you will get good milk cows out of this stock. 


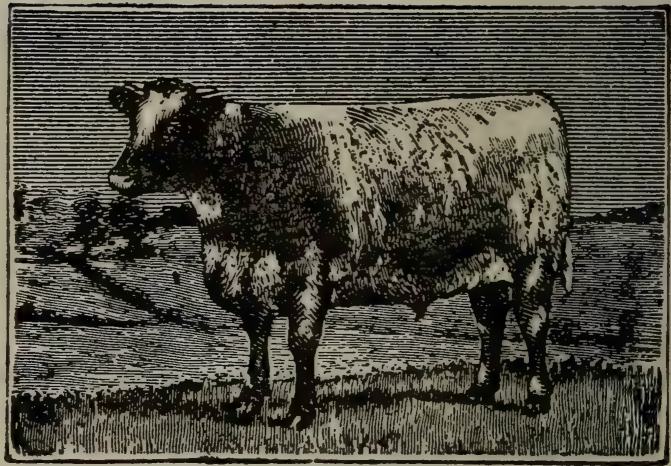

Roan Durham Male Calf.-Thé Roan Durham cattle are as good a stock as there is on the market. They are wide between the eyes, wide and short below the eyes; wide behind the ears; a heavy bone and a big foot for a male. The closer the privates are to the belly the more sure they are for a male of any bred. Look for the points; what is said about high breed stock of any breed, young or old. When looking for a male calf, look for a big eye; and stands with its head up so that it shows the style. 


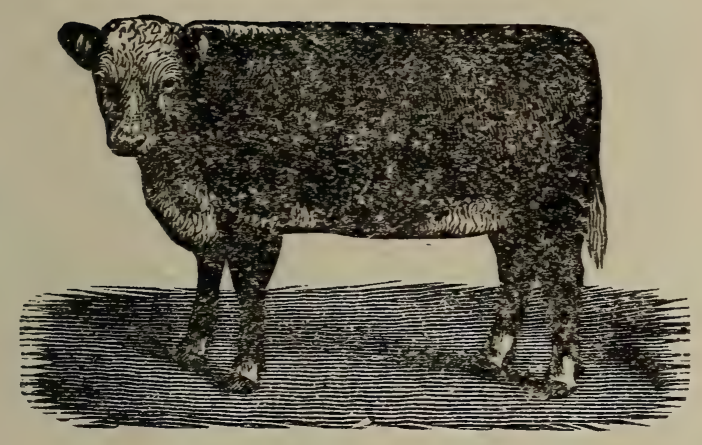

The Fullblood Hereford Heifer.-Tl e Hereford has a white face, white behind the horus, down $\mathrm{t}(\mathrm{)}$ and from the breast, including the beliy. a white streak across the shoulders and sometimes white across the kidneys. White on the end of the tail.

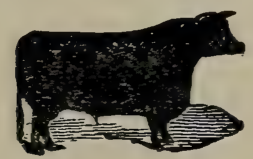

The Shorthorn Durham Male. - They have some white spots on them. They are a smooth built cattle. They are a scod thrifty growth cattle and easy feeders. 


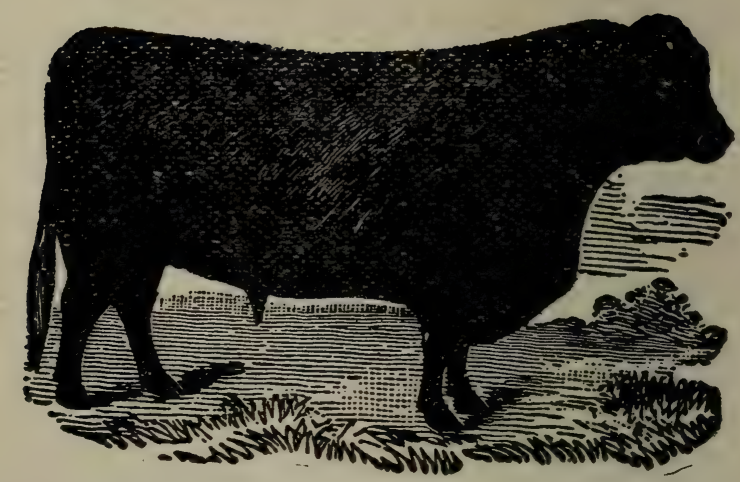

The Aberdeen Angus Male.-The Aberdeen Angus is black in color. They are a good beef cattle. They are a long, heavy, wellbuilt cattle but not good milkers. If you look for the milking points you may find some good milkers.

The Devonshire Cow.-The Devons are recommended as an all purpose breed for a farmer. In color they are red and are of medium size. They are fair milkers and good beef cattle. In a fullblood the points of the horns turn in, and they also have a fair sized ear; wide in the hips and a little rough. 


\section{CATTLE}

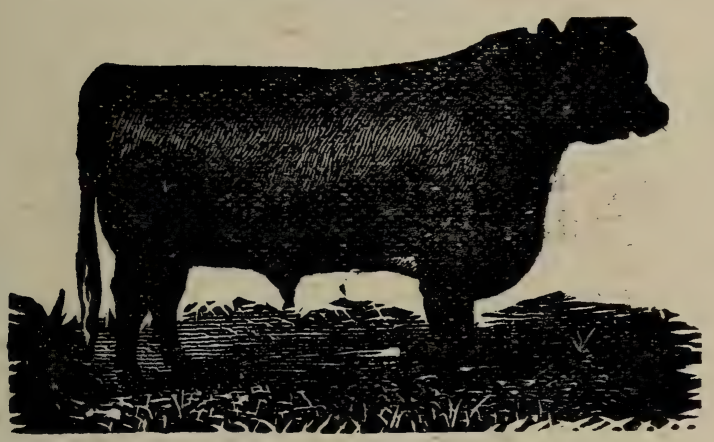

The Jersey Male. - The Jersey Male has a yellow skin. This picture shows that he is crossed some witl the Aberdeen Angus Don't get a Jersey with this cross because you can make that cross yourself.

Picking Beef Cattle.--Long and straight in the back, wide across the forehead, a wide jaw. This shows a good strong feeder. Short in the neck, heavy forequarter, heavy brisket, heavy bone, big foot, wide behind the shoulder, wide across the kidneys, low flank, low hind-quarter and wide across below the tail; straight in the belly, broad in the hind knee, a good hay basket, tand up squarely and head up. These points are for good steers. For a heifer, longer and slimmer from the eyes down, 
and look for a wide jaw of any good feeder.

How to Tell High Bred Cattle of any Breed. - The head higher than the shoulder, no low neck on young or old cattle, if low in neck, on a calf puli up on the neck once in a while as it grows which will help to straighten the low part of the neck. Straight in the back, heavy at the top of the tail and slim at the bottom, low in the flank and a long quarter, a heavy bone, straight in the belly, stand squarely on their feet and a low heavy brisket. For cows or heifers; slim in the neck, heavy in the forequarter, long from the eyes down and slim, wide between the eyes, small, thin ear, round at the top of the ear; the less hair in inside of ear shows high bred stock. You could see on a calf that isn't more thau an hour old. This shows on any breed of stock, young or old.

How to Tell a Good Milk Cow. - Look for an easy churner, yellow on the inside of the ear and yellow skin. The more the hair grows up the milk sack, the richer the 
milk. Watch the curls and the more they curl up the betıer the milk. When the milk sack begins to break up one of the udders draws up; when two udders draw up on the same side the cow don't give as much milk on that side as the side not thus effected. When the sack is clear broken down it is slim at the top and wide at the bottom. For an easy milker the udders hang down alike and are square or even in length. A hard milker has a long pointed udder. A big milk vein is a good sign of lots of milk. The larger the hole at the navei the chances are for more milk. The more the sack shows in front of the le; the more milk. The hair too white at th sack or the back part of the sack, the chances are for whiter cream. When the sack is too fleshy the udders are too far apart from the back part of the sack to the frorit part. No hair at all down on the back part of the sack and the udders yellow are symptoms of very rich milk. The chances are with these points, that the cream can be stirred and made into butter without putting the cream in the churn. 
Any cow should be yellow from the root of the tail down to the bottom of the sack with yellow udders, no hair on the sides of sack next to limbs. Here are fifteen of the best points on a milk cow. These points are for a man, woman or a fifteen-year-old boy to tell.

These Points On a Milk Cow are Some of the People's Points.-1. A black tongue. 2. Broad nose. 3. Long mouth. 4. The skin hanging loose on it's jaws. 5. A dish face. 6. Wide between the eyes. 7. A big eye. 8. A dent in the forehead. 9. A big ear. IO. A crumply horn. II. Little horns. 12. A pointy brisket. 13. Heavy and broad brisket. I4. A big foot. I5. A spotted foot. 16. A slim neck. I7. Long in the back. I8. Wide from the back bone out. I9. A big stomach. 20. Wide in the hips. 21. A slim tail. 22. A black switch. 23. The navel heavy. 24 . Up-headed with style. 25. Wide in the breast. 26. A yellow nose. 27. Part the hair, on the end of the tail is yellow. 28. A high tail bone. 29. Wide across the quarters and taper forward. 30. Wide open nostrils. 


\section{POINTS ON A MILK COW}

I. Wind udder is the same thickness from the sack down, where other udders are slimmer. Squeeze on the udder and sometimes water will come out.

2. When you find a cow that the udder don't look right, you had better milk her.

3. A cow that lets her milk down and then stops and lets it down again is a sign that most cows will stand dry too long.

4. A two story sack is one with a crease, across the middle of the sack behind, the top of the sack out and the lower part in. This is a good milk cow but the sack does not show up good.

How to Pick a Calf for a Milk Cow.-Yellow inside of the ears for an easy churner and yellow from the thick part of the tail down, where the sack ought to be and the hair short and curls up. These marks are for rich milk. These points will show on a calf as well as on a cow, and this kind of a calf will make a good milk cow when the time comes to be a cow. Also a large navel on heifer calt. 
Raising Calves.-Having selected a desirable breed, the farmer should begin at once bestowing upon his cattle the best of care. Food and treatment have a great deal to do in determining therr form, size, and character.

Age For Breeding.-Heifers may be put to breeding when they are from 15 to 18 months old. If well cared for early breeding has but little influence on the growth of the cow, and it develops the milking qualities much better. If left until two or three years before breeding, cows are much more likely to become barren.

Diseases of Cattle.-Although cattle are subject to some diseases which cannot be guarded against, yet most of them are the result of the want of care. Want of proper care, over-feeding or unwholesome food, exposure to cold winds, rain and snow, either of these, or all combined, may cause most of what are called "The Diseases of Cattle."

To the farmer, especially, is an ounce of prevention worth a pound of cure. 
The following are some of the most com mon ailments of cattle, with approved remedies:

GARGET.-A congestion of the udder, commonly known as "the caked bag." It most generally occurs soon after calving or when the cow is drying up.

Symprums.-Udder swollen, hot and very tender. Soon one of the teats begins to feel hard, afterwards others are implicated.

Causk.-Garget is caused by milk coagulating in the udder, producing local in. flammation.

Treatment.--Bathe the udder frequently with warm water and rub it gently with the hand. A solution of bicarbonate of soda injected into the udder will dissolve the caked milk. It should be milked out after remaining in the bag ten minutes. Another remedy suggested is two quarts of dried beans boiled and fed with the water. Two $r$ three doses will effect a cure. As a prevention, the udder should be examined frequently before calving, and if it becomes filled with milk, should 
be drawn. The cow should be fed sparingly with fresh hay, and when the calf is dropped, she should be milked frequently.

Milk Fever.-'This is a local inflammation of the womb after calving, which rapidly extends to other parts until the whole system is implicated, and puerperal or milk fever appears.

Symptoms. - The animal becomes restless and uneasy, red eyes, horns and head hot. She is irritable; at last becomes weak in the limbs and unable to rise; dashes her head about, not unfrequently breaking her horns.

Cause.-Exposure at the time of, and after, calving; also drinking freely of cold water at that time. Cows that are feed freely on exciting food for some time before calving are liable to have this disease.

Treatment.-If a veternary surgeon can be reached call him at once; if not, on the first appearance of symptoms, give one pound of epsom salts. The bowels must be opened. The entire body should be covered with a wet sheet or blanket. The 


\section{CATTLE}

best prevention of this disease is in taking good care of the cow before and after calving.

Abortion ur Premature Pirth.--This is a disease and is considered by many contaglous. It is known to be epidemic in gestation. The calf is always lost and the cow frequently dies. If the cow lives she will probably drop her next calf at about the same period of pregnancy.

Symptoms.-Aversion to food, milk diminishes: somewhat enlarged belly; staggers when walking; a reddish or yellowish fluid discharged from vagina; occurring at any time during the nine months of pregnancy.

Cause.-Aboration may be the result of fright, injury, or improper foor or water, diseased male, and commence with him after conception.

Treatment.- Separate the cow from the herd. After the calf is dropped, which is nearly always dead, bury it deeply, with the afterbirth, outside of the pasture or yard; use disinfectants to prevent the dis- 
ease spreading. Afterwards, the cow should be protected from exposure, giving no cold water and be fed on nourishing but not exciting food. Aboration becomes a habit; a cow that has once lost her calf prematurely should not be permitted to become pregnant again. Fatten her for beef, for she is of no value as a breeder.

Fast Driving of Cuws.-It should not be permitted on the farm. Boys should not be allowed to hurry them when bringing them in for milking.

Lost Cud.-The popular name for weakness is the result of indigestion, and may be cured by giving the animal a pint of raw linseed oil.

Corn Smut.-Cattle running on stock fields in the winter should always have plenty of water. Smutty cornstalks eaten without a good supply of water often cause disease.

Scours.-Caused by over-feeding, bad fuod or drink, damp stables, dirty surroundings. Remove cause and withhold feed is the best remedy. Give once daily 
twenty grains of potassium permagranite in a teacup of water.

Another good remedy is a teaspoonful of alum every day until relieved.

Lock JAw.-A constant muscular spasm involving more or less the entire body. It is caused by entrance of tetanus germs through a wound. There is stiffness of the whole or part of the body, more frequently the jaws, making eating difficult or impossible.

If the animal can drink give one-halfounce doses of bromide potash five times daily, dissolve and place on food or gruel or in water given to drink. Drench, and keep quiet.

When a cow is having a calf always allow her to eat the cleanings.

When a Cow Beclomes Numb.-The skin on the backbone becomes tight on the bone. Take your hands and loosen the skin from the shoulders back. The wolf in the tail: The bone becomes soft. Pull the tail several times each morning for three mornings. Every month examine 
the cow and see that the bone in the tail is not soft and that the skin on the backbone is kept luose. This is what weakens the cow and keeps her poor, and will make the milk blue and the cream thin. It will effect a fat cow the same as a poor one.

Swollen Udder. - To relieve this bathe the swollen parts in warm water in winter, using cold in summer.

After Calving.--If a cow does not clean herself, give her warm feed, and as a last resort, give her a dog button. Sometimes by allowing her to drink her own milk will aid in cleaning.

Before Calving.--For twelve hours before calving a cow should not be fed anything, and not too much afterward. Always milk a cow before calving, for it is sometimes the cause of milk fever.

To Remove Warts From Udder.Place a thin paste or slacked lime mixed with water on the wart several times and wart will disappear.

Tea for Calves. - In case you are feeding calves milk and run short, make a tea 
of clover hay and pour into the milk. It furnishes a great amount of nutrition.

Excess of FEeD. - If a cow has had too much feed and is still moist on the nose and chews her cud she is all right. But when these symptons fail you should give her a physic at once. The following is excellent: Six drops of croton oil in a pint of linseed oil, or a pint of lard.

To Prevent a Bull From Jumping.Put a wire through the nose about six feet long, and then double and twist it, and the bull will not jump.

Calves.-Feed calves shelled corn as soon as you can get them to eat it.

Some cows' milk will have the cream mized all through the milk in streaks. This kind of milk takes too long for the cream to raise. If you have a cow of this kind, keep the milk to itself. This is not a profitable cow to keep.

How tu Tell the Age of Cattle by ThE TeETh.-The calf at birth will usually have two incisors or front teeth, in some cases just appearing through the gurns, in 
others fully set, varying as the cow falls short of or exceeds her regular time of calving. If she overruns several days the teeth will have set and attained considerable size. During the second week a tooth will generally be added on each side, and before the end of the third week the animal will generally have six incisor teeth, and in a week from that time the full number of incisors have appeared.

These teeth are temporary, and are often called milk teeth. Their edge is very sharp, and as the animal begins to live upon more solid food this edge becomes worn, showing the long part of the teeth beneath, and indicates with considerable precision the length of time they have been used. The center, or oldest teeth, show the marks of age first, and often become somewhat worn before the corner teeth ap pear. At eight weeks the four inch teeth are nearly as sharp as before. They ap. pear to be worn not so much on the outer edge or line of the tooth as inside this line, but after this the edge begins gradually to lose its sharpness and to present a more 


\section{CATTLE}

flattened surface, while the next teeth wear down like the four center ones, and at three months this wearing off is very apparent, till at four months all the incisor teeth appear worn, but the inner ones most. Now the teeth begin slowly to diminish in size by a kind of contraction as well as wearing down, and the distance apart becomes more and more apparent The teeth keep getting smaller and farther apart until the calf is fifteen months old, when the corner teeth are not more than half the original size, and the center ones still smaller. The permanent teeth are now rapidly growing and preparing to take the place of the milk teeth, which are gradually absurbed till they disappear or are pushed out to give place to the two permanent central incisors, which show's the internal structure of the lower jaw, at this time, with the cells of the teeth. The two central ones protruding into the mouth, the next two pushing up, but not quite grown, to the surface, with the third pair just perceptible. These changes require time, and at two years past, four of the 
permanent central incisors are seen. After this the other milk teeth decrease rapidly, but are slow to disappear, and at three years old the third pair of permanent teeth are but formed, and at four years the last pair of incisors will be up, but the outside ones are not fully grown and the beast can hardly be said to be full-mouthed till the age of five years. But before this age, or at the age of four years, the two inner pairs of permanent teeth are beginning to wear at the edges, while at five years old the whole set becomes somewhat worn down at the top, and on the center ones a dark line appears in the middle along a line of harder bone. Now will soun come a vear or two, and sometimes three, when the teeth do not so clearly indicate the exact age, and the judgment must be guided by the extent to which the dark middle lines are worn. This will depend somewhat upon the exposure and feeding of the animal; but at seven years these lines extend over all the teeth. At eight years another change begins which cannot be mistaken. A kind of absorption begins 
with the two central incisors, slow at first, but perceptible, and these two teeth become smaller than the rest, while the dark lines are worn into one in all but the corner teeth, till at ten years four of the central incisors have become smaller than the corner ones, and at twelve all become smaller than they were, while the dark lines are nearly gone, except in the corner teeth, and the inner edge is worn to the gum.

To Help a Cow in Calving.-Pull down and steady on the calf when the cow strains. If she has a hard time, grease around with lard.

When you let the calf run with the cow, don't feed strong feed, as it makes the milk too strong, and it will curd in the stomach. It is liable to kill the calf if you are not careful.

Don't give a hand-fed calf curdled milk, as it will cause them to bloat, and often kill them.

For Cow That Has Taken Cold.-First Dose-Take one tablespoonful of aseofet- 
ida and mix with one-half pint warm water and drench.

Second Dose-One teaspoonful of the above in I 2 hours, the next morning a table spoonful. If cow is billious, give physic. Use same physic as you would on foundered cow.

To Vomit a Cow.-Two tablespoonful of baking soda, one teacupful of molasses, one-half pint of warm water, and drench; repeat the dose in two hours if necessary. To be used in cases of overeating such as apples, corn, or if bloated with clover.

To Unchoke a Cow.-For a hard substance like a nubbin of corn, drench with lard. If an apple or potato or anything soft, take two square blocks and strike on outside of throat and flatten the article, when it will either go up or down.

The DAIRY.--I run a dairy for five years. When I wanted to turn a cow dry I quit milking her. Then on the second day I milked her again, then waited three days and milked again, and so on. I never had a cow's udder to cake unless it was 
hurt or stung. Never had a cow to lose her teat unless it was caused from a bruise or a sting. Leaving the hot milk in the bag is what dries up the cow. Sometimes the milk will be blue and the cream thin on the milk. You should examine your cows to see if they have any disease. Don't forget to keep the skin loose on the back and watch for the wolf in the tail, as a fat cow is as apt to have it as a poor one. Give your cows a little salt every day as it will improve the milk and butter.

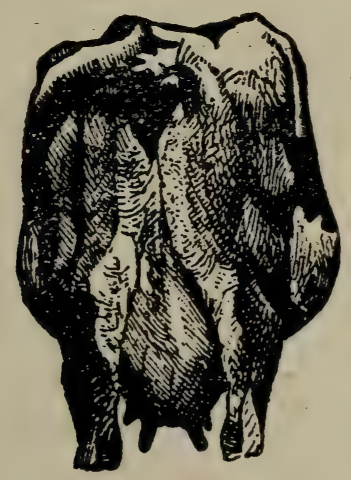

\section{Points for a Good Milk Cow}

Here, boy, look for the curls that curl upwards, and the hair on the sack should grow upwards instead of downwards, the sack should feel greasy. 'These are symptoms of a good milker. 


\section{SHEEP}

$0-00000-0000000000-0000$ 


\section{SHEEP}

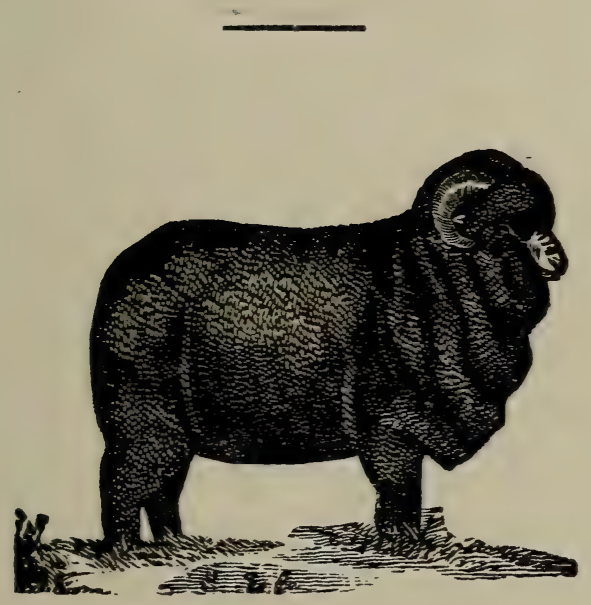

\section{THE MERINO SHEEP}

The Merino is a healthy sheep and has a good heavy fleece. A large number of them could be herded together and stasd inore rain and cold without any danger. They are a lucky breed to raise lambs. Any sheep wants to show a large eye. 


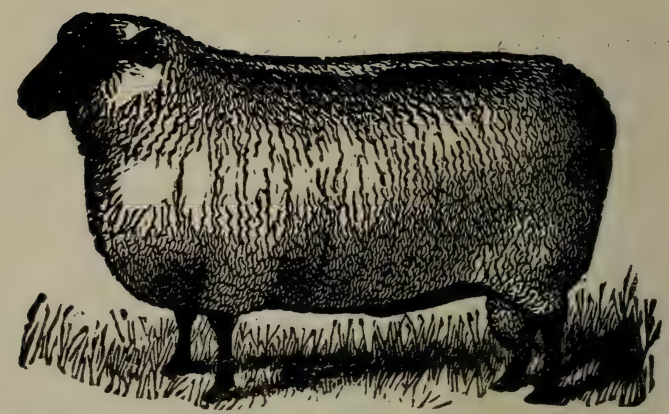

\section{THE FULLBLOOD SOUTHDOWN SHEEP}

The older the sheep the slimmer the neck and straight in the back. A high bred sheep don't tuck their tail down as much as one that is not high bred. The quarters to come out square and straight down. The wool low down on the limb. Straight in the belly. A full breast. The wool to come down under the jaw and between the eyes. The more the wool comes down over the face the higher they are bred. Don't want bald place between the ears. A stylish sheep wants to stand squarely on his feet with his head up. The redder the limb and the redder the face the higher the South Down are bred. The blacker the limbs and the blacker the face the higher the Shropshire are bred. The lower the wool is on the forehead the higher they are bred on the most of breeds. 


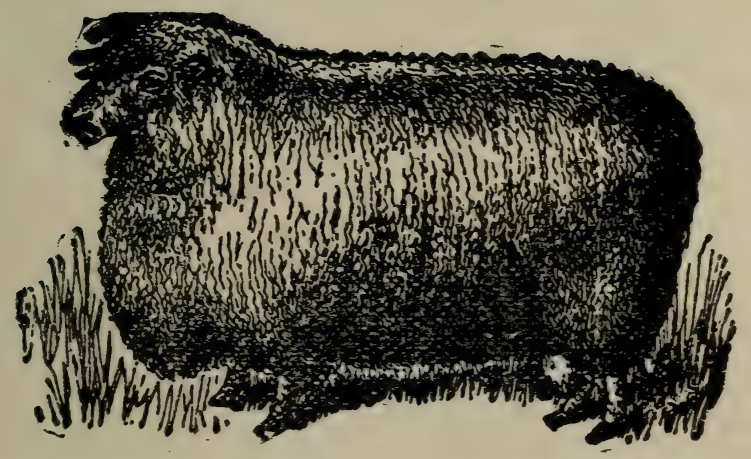

THE FULLBLOOU COTSWOLD SHEEP

On a Cotswold sheep the whiter the limb and the whiter the face the higher thev are bred. Some other breeds have the same points. The Cotswold is a good wool sheep and the lambs bring big money. They should also show a large ear and a large eve. 


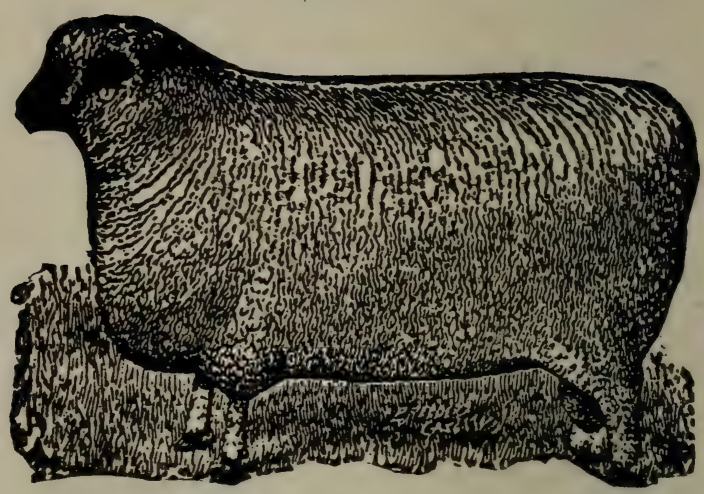

\section{THE COTSWOLD SHEEP}

The Shropshire sheep crossed with the Cotswold, the wool longer. The whiter the limbs and the whiter the face the more they are crossed with the Cotsivold.

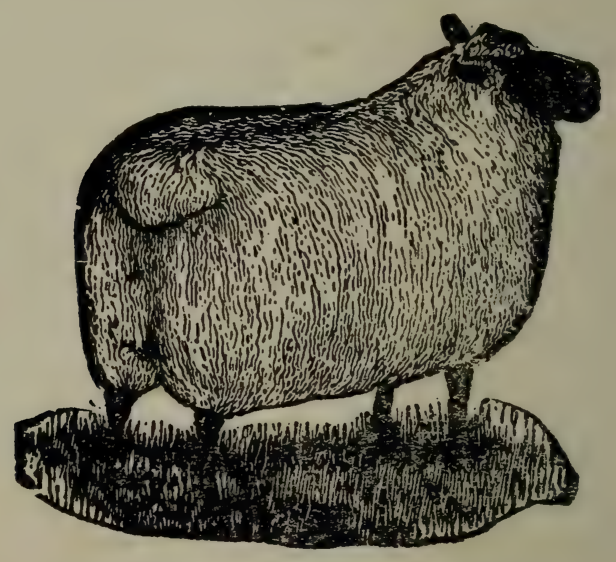

THE SHROPSHIRE SHEEP

The Shropshire are a nicely built sheep 
and weigh heavy. Youcan make this cross yourself without paying for the pedigree. The blacker the face and the blacker the limb the higher the Shropshire is bred.

The Ewe During Pregnancy.--The ewes should be well cared for, and those expected to drop their lambs early in the spring, closely watched.

As the time approaches for finding lambs, the ewe should be separated from the flock and placed in comfortable quarters.

Ewes should be fed well during their entire pregnancy, but not kept fat. They should also have exercise.

IVEAning Time.-The ewe should have a dry, warm place, where she and her newlyborn lambs can be provided with shelter from wet and cold. A shed enclosed so as to shut off the wind will answer. If the weather is very cold they should be better protected, so as to keep warm.

If the lambs come later in the season and for the general flock about the first of May is the best time-less shelter and less care generally will be required. The main 
thing at any time is to prevent either the ewe or young lamb from becoming chilled.

The Young LamB.--After the lamb is dropped the ewe will generally lick it dry. If, however, she refuses to do this, it should be carefully wiped dry. The lamb will soon attempt to suckle; if it does not it should be assisted. If the ewe refuses to own the lamb she should be held while it suckles. If this is repeated a $\mathrm{f} \in \mathrm{w}$ days she will generally own it. Another way to make a ewe own her lamb is to put some paint on the lamb's back, or put linseed oil on the ewe's nose. This will change the smell. If the lamb is not sufficiently strong to reach the teats it should be assisted once or twice. Any locks of wool upon the ewe's udder that may be in the way should be clipped. If the ewe refuses to own the lamb she may be confined between two small hurdles. Two light stakes are driven in the ground, close together, to confine the ewe's head and keep her from butting the lamb. If she is disposed to lie down as some obstinate ones will do, a light pole is passed through the hurdles, 
resting upon the lower bar, beneath her belly. Thus confined during the day, she is helpless, and if the lamb is lively, it will manage to get its supply of food. She should be released at night. One day's confinemerit is often sufficient to bring an obstinate ewe to reason.

A Twin Lamb, or one deprived of its dam, that may need to be reared by hand, may be easily fed on cow's milk. A fresh cow's milk is the best fitted for this purpose. Ewe's milk is richer in solid matter than that of a cow, and the addition of a teaspoonful of white, refined sugar to the pint of cow's milk, will make it more palatable to the lamb. At first, not more than a quarter of a pint of milk should be given at once. The milk should be freshly drawn from the cow and warmed up to one hundred degrees before it is fed.

A convenient method of feeding milk to a lamb is to use a small tin can with a long spout, such as is used for oil. An air hole is punched in the cover or cork and a piece of sponge covered with a cloth is tied upon the end of the spout. The flow is thus 
made easy and equal, and the lamb sucks in a natural manner. A very short time is sufficient to familiarize the lamb with this kind of foster mother.

To encourage the flow of milk in the ewe and the corresponding growth of the lambs, the food of the ewes should be of the best. Clover hay, bran, and crushed oats, with some pea-meal are the most preferable foods, producing a rich milk in abundance. The ewes must not be allowed to fall off in condition or the lambs will fail. During mild weather, sugar beets may be given in moderate quantity with advantage, but mangels or Swede turnips (rutubagas) should be avoided, as too watery and deficient in nourishment, and productive of scours in the lamb. In cold weather roots are apt to reduce the temperature of the animal too suddenly if given in any but small quantities, and consequently decreases the flow of milk. Pea straw is a favorite and nutritious for sheep, but it will be found to be profitable to give only the best at hand to nursing ewes. The after growth and condition of lambs depend greatly upon the maintenance of a thriftly 


\section{SHEEP}

and continuous growth during the first three months.

As soon as the lamb is dropped and the ewe has revived and licked it and the lamb has once sucked, all danger is passed, except from gross carelessness.

The ewe will be greatly helped by a drink of slightly warm thin oatmeal gruel, well salted. The lamb will be benefited by a teaspoonful of castor oil, given in new milk, if the first evacuations do not pass away freely. They are apt to be very glutinous and sticky, and, by adhermg to the wool to close the bowels completely unless removed. Warm water should be used to soften and remove these accumulations. The anus and surrounding wool should then be smeared with pure castor oil. If the lamb is scoured, a teaspoonful of a mixture of one pint of peppermint water and one ounce of prepared chalk should be given every three hours until it is relieved.

If the lamb is intended for early market it should be taught to eat while quite young. Feeding may begin at about three weeks 


\section{SHEEP}

of age. Indian meal or oat meal gruel may be given it. The ewe, at the same time should be fed bran, oil cake or oatmeal. Heating food, like corn, should not be given her. The lamb, in a very short time, may be giving oats or hay.

WEANING - Lambs should be weaned when about four months old. They may be left in the pasture where they have been running with the ewes, and the ewes removed to some other place and put upon dry food to stop the flow of milk. Their udders should be watched, and if they become distended, should be relieved by milking. If at all feverish they should be bathed in tepid water.

AGE.- The age of a sheep may be ascertained by examining the front teeth, which are eight in number, and make their appearance during the first vear, when they are all of small size. The following year the two midule teeth are superseded by two others of larger size. During the third year, two otiler smaller teeth, one on each side, are shed and their places 
filled by large ones. At this time there are four large teeth in front flanked by two pointed ones. The fourth year, the large teeth are six in number and only two small teeth remain, one on each side. These disappear during the fifth year, when all the front teeth are large. Signs of wear are generally visible during the sixth year, and during the seventh year, sometimes even earlier, they begin to fall out, and are broken off.

Miscellaneous. - Sell your sheep, if possible to those who consume them; you will thus secure better prices. A good farmer says that he sells every year, in lambs and wool, an average of five dollars per head for each of his flock.

Breeding ewes should be feed judiciously.

Old sheep do not pay for their keeping. I ewe should not bear more than four sets of lambs.

Be gentle with your sheep; they are naturally shy, but if treated well become very affectionate.

Salting is very necessary to the health of sheep. If salt can be placed where they 
can get it whenever they wish, winter and summer, it would be a better plan than to give it at regular intervals.

Exercise is a necessity to the health and well being of a sheep. In the summer they get it on the pasture. They should have it in the winter by having access to dry yards.

TAGging.-Before turning the sheep from their winter quarters on pasture in the spring, they should be tagged. 'Tagging is simply the removel of such wool as is likely to get fouled. All the wool around the neck and from the ruots of the tail down the inside of the thigh is cut away.

Docking. - This is the process of cutting off the tails of lambs, and is generally done at the same time that castration is performed. It should always be done in cool weather, and when the lamb is three or our weeks old. The tail is laid on a block and cut off with a chisel, at one blow, with a mallet. The stump is left about two inches long. To prevent flies, take a hot iron and singe the tail. This will stop the blood. 


\section{SHEEP}

Sc A B.- Another contagious disease caused by a small insect burrowing in the skin, producing an intense itching. The rubbing or'scratching of the atimal results in scab. The wool comes of in patches, and the animal pines away.

Sympтомs.-Restlessness, violent rubbing against trees, fences, etc., scratching with its feet, biting sores and tearing off wool.

Treatment.-Dip in strong solution of tobacco, with a little blue vitriol added; isolate affected sheep from flock.

Another remedy is to separate the sheep. Do this first, for it is verv infectious; then cut off the wool as far as the skin feels hard to the finger. The scab should theri be thoroughly washed with soapsuds and rubbeu hard with a shoe brush, so as to cleanse and break the scab. Make a strong decotion of tobacco; add one-third, by measure, of strong lye of wood ashes, and as much hog's lard as will be absorbed by the lye, and about one-eighth of the whole, by measure, of the spirits of turpentine. This decotion should be rubbed upon the 
parts affected, and some distance outside of it. It should be applied until cured. Another remedy is to dip the sheep in an infusion of arsenic, in the proportion of one-half a pound of arsenic to twelve gallons of water. The sheep should previously be washed with soap and water, and great care should be taken that the infusion does not enter the mouth or nostrils.

Garft.-A hot, hard, or caked udder; sometimes occurs with young ewes after birth of first lambs; and also with ewes of any age after weaning their lambs; caused by an accumulation of milk in the udder.

Treatment.-Bathe with quite warm water, with a little opium or laudanum added, applying several times daily.

DIARRHEA.- Sheep changed from dry food to grass frequently have it. Remove from pasture and give only dry food for a few days. Give a little prepared chalk to lambs afflicted.

Tıcks.- Ticks are sometimes very annoying to young lambs.

Dip them in a strong decoction of to- 
bacco. A mixture of one gallon of soft soap, six pounds grease, one pint crude carbolic acid, all boiled in ten gallons water, with nine gallons of cold water added, makes a good dip.

Foot Rut. - A contagious disease of the foot where the hoofs unite with the bony structure, and in the cleft between the hoofs. If not attended to at once, it suppurates and becomes very painfnl to the sheep. Finally the hoofs come off and the sheep is lost.

Symptoms.--The first symptoms appears in the usually dry and colorless naked skin at the top of the cleft over the heels. It becomes a little inflamed, with a chafed appearence. The first part attacked becomes sore and ulcerous, extending down to the inner walls of the hoof. The ulceration gradually penetrates between tile fleshy sole and the botton of the hoof. The hoof finally comes off.

Cause.-Supposed to be in an undue amount of moisture under the feet, which softens the hoof and causes an inflammation of the tissues. 
Treatment.-Build a pen and cover the bottom with a mixture of clay and salt, deep enough to come over the hoof.

Another remedy is to pare off the diseased hoof; wash off the putrid matter, and apply this mixture:

Turpentine, two ounces.

Sulphric acid, two drachms.

Lard, one pound.

Tar, one-half pint.

After a treatment the animal should be kept on dry footing.

As soon as disease appears in a flock, the sheep affected should be isolated at once.

Grubs in the Head. -Caused by small bots or grubs, hatched in the nustrils of the sheep, from the eggs of the sheep botfly in the summer.

Symptoms.-Eyes swell, become weak and watery; sheep make violent efforts to clear their nostrils; restless, refuse food, and frequencly raise their hind legs as if in great pain.

Treatment.-Scatter slacked lime about their feeding places edrly in the morning, 
causing sheep to sneeze and expel the grubs.

A Shock to Kill Grubs.-A teaspoonful of gun powder put on a shovel and make a fuse out of paper, hold it six inches below the nose and touch it off. This will numb the grubs so the sheep can blow them out.

Another remedy is, to inject strong salt water up the nostrils with a syringe.

Another remedy is, to bathe the head and nose with an equal mixture of turpentine, and camphor and lard.

To Break a Dog From Killing Shenp. - Tie the dog to a dead sheep so he cannot get away. Give him a good whipping, and if he smells of the sheep whip him again. Leave him tied to the sheep for some time. This will sometimes break a dog.

To Keep a Sheep From Jumping.-Cut one of the hamstrings on each hind leg. Cut slow on it till it comes off.

Another remedy is, to put a strap around 
the neck, take a round stick about three feet long, bore a hole about three or four inches from the end, take a strap eight or ten inches long and tie to the collar. 


\section{HOGS}

00-000000-0000000000000 


\section{HOGS}

\section{POINTS ON ANY FULLBLOODED HOG, MALE OR FEMALE}

Wide between the eyes and the eye not too low down, wide between the ears, the ears thin and the tips of the ears tip in, in the place of out.

A Brood Sow, a little long from the eyes down, the back higher behind than in front, a low flank, the chances are then for an easier pigger, straight in the belly, the nipples well forward, see that there is no curl in the hair eight inches from the tall up the back on any breed. Thin behind the ears and the ears thin. A good bone and the ham low down. 


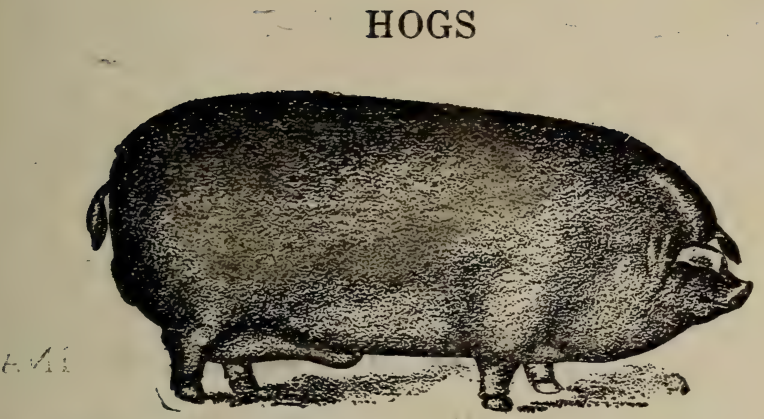

\section{A CROSS BETWEEN THE O. I. C. AND CHESTER WHITE}

If there is a cross with the Chester white in the O. I. C. the hair will be fine and thin, with a straight face and also a siim tail with a curl in it.

A Male Hog, straight in the back, short from the ear to the shoulder, heavy jowl, there should be no bollow under the shoulder, but the flesh low down under the leg. A little wider in front than behind and straight up and down on any breed of hogs. The shoulder straight down and not too heavy just above the knee for male or female for an easy pigger. For a male hog the wartier and rougher the privates are, and the closer and not too low down, also both of a size, the better are the chances for more pigs. 


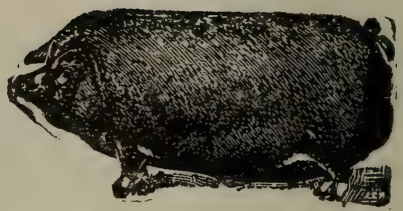

THE FULLBLOOD POLAND CHINA

White on the end of the tail. Four white feet. A white, straight face. Straight black hair. See that there is no curl in the hair about eight inches from the tail up the back. This does not show good breed. ing. The smoother the privates the less pigs. A heavy jowl and a thin ear. The ears tip down an inch and a half from the end of the ear and tip in, in the place of out.

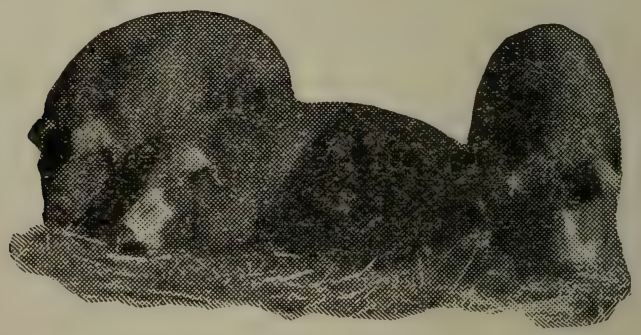

THE POLAND CHINA BROOD SOW

Look for the points on brood sows of any high bred sows. Look for the points that belong to the breed. 


\section{HOGS}

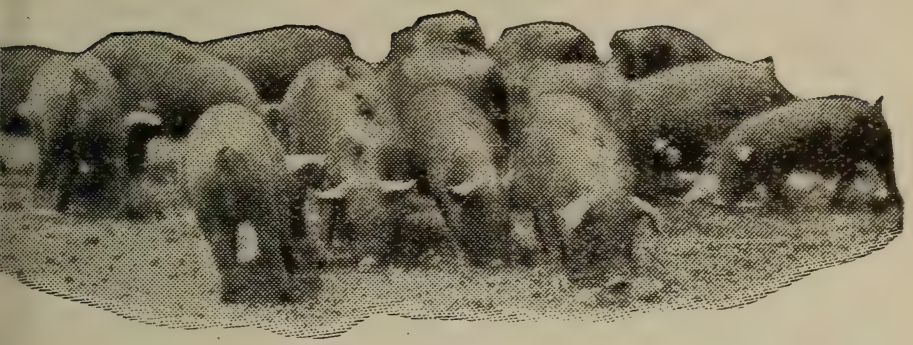

THE DUROC PIGS

Some of the Durocs have a dish face and the ears a little too straight and not rnough jowl, tuo fine a bone and $t(x)$ high a flank.

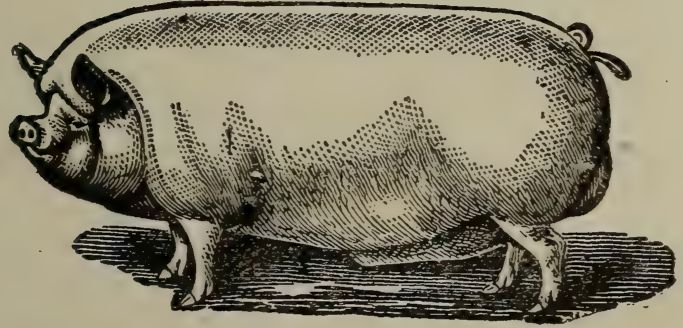

THE FULLBLOOD O. I. C.

A long heavy tail with not much of a curl in it. Long hair on the end of the tail. The more dish face the higher they are bred. Long, heavy, white hair. 


\section{HOGS}

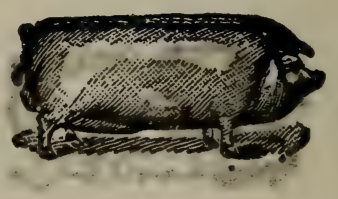

\section{THE CHESTER WHITE}

They have a straight face, straight ear and a thin ear. The hair on the body not so long. A small tail with a curl in it.

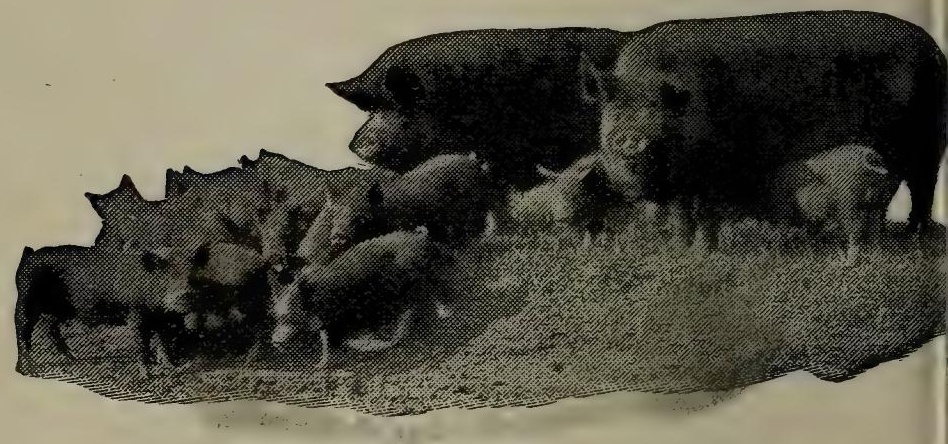

THE BERKSHIRE HOG

The Berkshire is a black, smooth haired hog. The end of the tail is white, four white feet, white nose and a dish face. The ears stand straight up. The Berkshire and Poland China are a good stock of 


\section{HOGS}

hogs for home or country use. The hams and shoulders do not show as much fat as some other breed. They show more lean meat, this is why they are used for home use.

\section{THE FULLBLOOD ESSEX}

Black curly hair, black tail, a straight ear. Four black feet. Black nose and a dish face. If there is a cross of the Essex with the Poland China some of the pigs will have black feet and black noses, and also a black tail.

\section{THE FULLBLOOD MCGEE POLAND CHINA}

White feet, white on the end of the tail and a straight white face. Black and small white spots all over them. White in the flank. The feet are white a little higher up than the Poland China.

\section{THE FULLBLOOD JERSEY HOG}

They have a body more like the Poland China, with a long, heavy tail and not much of a curl. The hair yellow on the feet, nose and top of the ear. The hair on the body is of fair length and vellow. If 
the skin is dark on the back it is crossed with some black breed. They have a thin straight ear and tip in instead of out. A straight face and a heavy jowl. The Jersey are bred from the Poland China.

For yourself, select whatever breed suits you best. Keep it pure, and select the best specimen and inprove it within itself.

After being bred, the sow should be lib. erally fed and in summer kept on clover or blue grass pasture. Young sows can hardly be made to fatten while carrying their first litter. They seldom overlay their first litter, being more careful and attentive than with subsequent litters.

During the winter season, when there is no green food or vegetation for animals, pregnant sows should not be confined to grain alone (oats are preferable to corn) nor kept in a small lot, but should be fed on turnips, beets, potatoes, or better still arti chokes.

When a sow has pigs, always allow her to eat the cleanings, and do not feed her until she comes out of the nest. 


\section{HOGS}

Hog Cholera.-A good recipe for hog cholera is as follows:

Phosphate lime, $8 \mathrm{nz}$.

Common chalk powder, 6 oz.

Carbonate magnesia, $2 \mathrm{oz}$.

Capsicum powder, $\frac{1}{2}$ oz.

Mix well tegether. Give as a preventive one or two teaspoonfuls in feed every day. As a cure, give one teaspoonful three times a day.

A good preventive of disease is to put pokeroot in the slop, and put carbolic acid around the trough.

Another good preventive for cholera is to take equal parts of coal oil, turpentine and sulphur, mix together, give one tablespoonful in slop once a day, for a hog that will weigh 150 pounds.

Keep the worms out of the hog and keep $h$ is blood pure and they will not be so likely to have disease.

When castrating pigs, if it should swell, do not cut it with a knife, but let it break itself.

Put salt in it to keep it running, and it will heal from the inside. 


\section{HOGS}

To help a sow when pigging, take a long shoe buttoner and hook in the pig's jaw and draw it out gently.

To make pigs strong and healthy, feed a sow coarse wheat bran made into a slop; feed the same as other slop for two weeks before and three or four days after pigging, then you may commeuce giving stronger slop.

If you want to get lengthy pigs, breed a sow to a lengthy male hog.

Always pick a sow high in the hams or back. She will not be so apt to drop her pigs before the time is up.

To Prevent a Hog From Catching Chickens. -Take a piece of Nic.I I wire about one foot long; take an awl and make a hole in the nose, put the wire through the hole and twist it so it will come down over the nose, and spread the ends of the wire about one inch apart. When the hog grabs at the chicken the wire will strike it before he can get to it. 


\section{HOGS}

Cholera.-The term cholera is employed to designate a disease which has been very fatal among swine in different parts of the United States, and for the reason that its symptoms, as well as the indications accompanying its termination, are nearly allied to what is manifested, in the disease of that name which visits man.

Epidemic cholera has for several years past committed fearful ravages among swine of, particularly, Ohio, Indiana and Kentucky. Indeed, many farmers who, until recently, have been accustomed to raise large numbers of the animals, are, in a great measure, disinclined to invest again in such stock on account of the severe losses, in some instances, to the extent of the entire drove upon particular places.

Various remedies have, of course, been prescribed, but the most have failed in nearly every case where the disease has secured a firm foothold.

Preventives are therefore the most that can be expected, and in this direction something must be done.

Although some peculiar change in the atmosphere is probably an infalliable cause 
of cholera, its ravages may be somewhat stay€d by removing other predisposing associate causes.

Granting that the hog is a filthy animal and fond of rooting among filth, it is by no means necessary to persist, for that reason, in surrounding him with all the nastiness possible, for even a hog, when penned up in a filthy place in company with a large number of other hogs, particularly when that place is improperly ventilated, is not as healthy as when the animals are kept together in smaller numbers in a clean and well ventilated barn or pen.

Look for a moment at a drove of hogs coming along the street, the animals all fat and ready for the knife. They have been driven several miles and are scarcely able to crawl along, many of them having to be carried on drays, while others have died on the road. At last they are driven into a pen, perhaps several inches deep with the manure and filth deposited there by hundreds of predecessors. Every hole in the ground has become a puddie and in such a 
place some one hundred or two hundred animals are piled together exhausted from the drive which they have had. They lie down in the rnud and in a short time one can see the steam beginning to rise from their bodies in volumes, increasing their already prostrate condition by the conse: quent inhalation of the noxious gas thus thrown off from the system. The blood becomes impregnated with poison. The various functions of the body are thereby imported and disease will inevitably be developed in one form or another. Should the disease known as hog cholera prevail in the neighborhood, the chances are greatly in favor of their being attacked by it and conseqnently perishing.

Symptoms.-The symptoms of cholera are as follows: The animal appears to be instantaneously deprived of energy, loss of appetite, lying down by himself, occasionally moving about slowly, as though experiencing some slight uneasiness internally. The eves have a very dull and sunken appearance, which increases with the disease; the evacuations are almost con- 
tinuous, of a dark color, having a fetid odor and containing a large quantity of bile; the extremities are cold and soreness is evinced when the abdomen is pressed; the pulse is quickened and sometimes hardly perceptible, while the buccol mem. brane that belong the cheek presents a slight purple hue, the tongue has a furred appearance, the evacuations continue fluid until the animal expires, which may be in twelve hours from the first attack, or the disease may run on for several days.

In a very short time after death the $a b$ domen becomes of a dark purple color and upon examination is found to contain but a little fluid, the intestines are almost entirely empty, retaining a slight quantity of the colored matter before mentioned. The mucous membrane of the alimentary canal exhibits considerable inflamuation, which sometimes appears only in patches, while the other parts are filled with dark venous blood indicating a breaking up of the capillary vessels in such places.

Treatment.-As a preventative the following will be found valuable: 


\section{HOGS}

Flour of sulphur, 6 lbs.

Animal charcoal, I lb.

Sulphate of iron, $6 \mathrm{oz}$.

Cinchona, pulverized, I $1 \mathrm{~b}$.

Mix well together in a large mortar, afterwards give a tablespoonful to each animal, mixed with a few potato peelings and corn meal, three times a days Continue this for one week, keeping the animal at the same time in a clean, dry place and not allowing many together.

The best preventative for cholera is to keep plenty of gympson stalks growing in the hog lot. This will keep the hogs healthy.

Bedding Hogs.--The best bedding for hogs is corn fodder. Just throw it in the pen and they will pick it to pieces and make a bed of it better than you could do yourself. The Chester White hogs have a very fine, thin coat of hair, and if you have many of them together and have not got a good bed for them they are apt to scald and the hair will drop off. Give them a bed of fodder, as it will keep the 
mange off of them and prevent them from scalding much better than a bed of straw or anything of that kind.

Crossing Hogs.-The Poland-China hogs crossed with the Jersey make a good cross, as the pigs will be of good size and hearty.

The Poland-China and the Berkshire make a good cross. The pure breed of Berkshire is more wild than the other breeds, and by crossing them with the Poland-China it makes a tamer hog.

Physic Hogs.-As soon as your hogs are complaining and lying around not eating good you should give them a good physic. The following is good for a hog weighing one hundred and fifty pouuds: Give one. fourth of a tablespoonful of powdered aloes; dissolve in water and put in the slop. If the first dose is not enough, repeat. This is as good a mild and as quick a physic as you can get for any kind of stock. If you should happen to give too large a physic, give flour and water to check it.

A good remedy for worms and the blood is to give equal parts of turpentine, coal 


\section{HOGS}

oil, and sulphur stirred in the slop. Give a tablespoonful once a day.

Lice.-A good thing to kill lice on hogs is, coal oil two parts, lard one part; mix and rub on the hoys. The coal oil will kill the lice, and the lard will keep it from taking the hair off.

Lameness in Hogs.-There is small holes or pores in the front leg, just above the knee, that sometimes get stopped up and make a hog lame. The places should be opened. They are hard to find, but if you take soap suds and wash them good, rubbing hard with a corncob or something of the kind, it will open them up and they will get better.

Feeding Pigs.-After weaning pigs do not give sweet milk alone as it will make them costive and in straining the rectum will sometimes turn out if it does the only remedy is to cut it off and feed some soft loose feed, when you are feeding milk you should feed corn soaked in water with it.

Salting Hogs.-Do not throw salt in the pen but give it to them in the slop. 


\section{HOGS}

Treatment and Care of the Sow.-After being bred the sow should be liberally fed and in summer kept on good clover or blue grass pasture. Young sows can hardly be made to fatten while carrying their first litter. They seldom overlay their pigs of their first litter being more careful and attentive than with subsequent litters. During the winter season when there is no green food pregnant sows should not be confined to feed on grain alone oats are preferable to corn, not kept in a small lot but should be fed at least once a day on turnips, beets, potatoes or artichokes if they can be had, if not, feed once a day shorts mixed into a slop, give them a large lot to run in so they will have ample room for exercise. If sheds are made for shelter put in partitions every six feet so as to prevent too many from sleeping together and piling up and over-laying each other, the sheds should be made with the cornmon shed roof the highest side facing to the south and the south side made with doors so that on bright days they can be opened to air, dry and purify the bedding 


\section{HOGS}

which greatly promotes the health of the swine. In the spring when your sows farrow, each one of these divisions can be used for a feeding pen and when used for that purpose you should put a slat around the bottom on the inside about 8 inches from the bottom and six inches from the sides so that when the sow lays down close to either side instead of catching a pig between her and the side of the pen it gives the pig a chance to get away, otherwise it would be certain death. Sows usually carry their young one hundred and twelve days, sometimes overrun a day or two but seldom fall short of that number. A week or ten days before farrowing the sow should be separated from the rest of the herd and put in a lot or pen by herself, supply her with good warm shelter and dry clean bedding, corn husks make the best bed. At farrowing if in cold or chilly weather the pigs should be wiped dry with a woolen cloth as soon as born, then placed in a warm box until the sow is through when the pigs should be placed at the teats of the sow. But in all cases the 


\section{HOGS}

sow should be watched at farrowing as she frequently needs assistance and almost always attention. It is possible that fourfifths of the pigs that are overlaid and killed by the sow are killed by her during the struggles and agonies of labor. Do not disturb the sow so as to make her rise until all is over and not then if it can be avoided and let her remain quiet for at least six hours giving her only water to drink and not much feed for six hours, nor should she have more than half feed the day before farrowing. The second day give her a thin slop, the third day slop and an ear of corn three times a day, the fourth day double the feed after that increase her feed until the seventh day when she should have all she can eat.

If the pigs get the scours feed only dry corn for a few days. If this does not stop them, give sweet skimmed milk thickened with flour of milk alone with corn or shorts and sulphur. As soon as you can after farrowing remove the wet part of the bedding and sprinkle a little pulverized copperas in the bed to disinfect and purify it 
from the disagreeable oder arising after farrowing. Sows, after the first litter, do better to be kept in good, thrifty condition, say half fattened. When in farrow in this condition they are more careful than when very fat and not so apt to overlay their young. During the sucking season the sow should be fed as much as she will eat and have the run of a grass field if possible. Sows will generally take the boar within three days after farrowing and sometimes get with pigs, but after that period they rarely come in heat until three or four days after the pigs are weaned. As a iule it is better to breed your sows but twice a year, and regulate it so that the pigs will come the last of February or the first of March and from the middle of September to the middle of October. June, July, August, November, December an January pigs are generally unprofitable, extreme warm or cold weather being alike unfavorable for success. Sows may be safely bred when they are eight months of age without detriment if generously fed. 
But one litter the first season is recommended. After they are in their second year they may be safely bred twice a year. Such a course, in fact, is deemed desirable, as they are much less liable to become sterile than when allowed to run without breeding. Some persorss object to breeding their sows until they are one year old. But a breed of hogs that does not have sufficient size and vitality to breed at eight months cannot be regarded as having the profitable quality of early maturity.

How, When and What to Feed Your Pigs. -As soon as the pigs begin to tat, provide a small trough in a part of the pen or lot where the sow cannot get to it. Into this pour a half pint or a pint of sweet milk weakeued with water, gradually increasing the quantity as they grow older. Let them drink what they wil! of it, but always clean it out before feeding again. When two or three weeks old, give them, a quiet place by themselves a little soaked corn. Soak the corn in cold water about twenty-four hours before using. Oats prepared in the same way are still 


\section{HOGS}

better or growth and vigorous development, but do not fatten a pig so rapidly on corn. It will be better to use a mixture of both, whole or ground together, or if you prefer it, cook the feed instead of soaking in cold water. The soaking you will find much less troublesome and equally profitable.

To Keep Brood Sows Over Winter.Give them plenty of corn fodder for bedding, and they will not lose a hair.

To Stop a Hog From Eating Chickens.Take two wires, each one foot long, and take a knife and cut a hole through the nose, where you put in rings, one on each side of nose. Stick the wire through, giving one or two twists; tie them together close to the nose with wire so they can't come apart, bend wire down right over the mouth, then, when they make the uive after the chicken, the wire is between them and the chicken.

Breachy Hog.-Take a wire twelve inches long, put it through the center of the nose let it hang down over the mouth, 
turning the end up so it will catch on rails or boards.

Physic for Cows.-Milk Fever.-One to two pounds of Epsom salts in a gallon of water, with a spoonful of ginger. Turn the cow over her feet once or twice a day. Don't turn over the back.

Give the cow about a tablespoonful of gun powder in a nubbin of corn to make her clean herself after calving.

Another Remedy-A piece of pickled pork about two inches wide and four inches long.

Also a dog button pulverized fine and mixed with about a tinful of bran.

Thumps--In pigs is caused by the pigs not having enough exercise and two much dust in the pen.

Remedy.--One teaspoonful of gun camphor to three tablespoonfulls of water or whiskey and one tablesboonful of hot lard. Stir well, and take breath and put in nose and mouth. 



\section{POULTRY $00-0000-00000-000-00000$}




\section{POULTRY}

\section{FOR HIGH BRED CHICKENS OF ANY BREED}

Straight up behind and also straight in front. Head and tail close together. Hen a little longer in the back than a crower. A good sized limb for any breed of chickens and a long toe, also a fat heel so that they will stand up squarely and show their style. For a laying hen, they are wide across the thigh and tapering forward. When they are the same width behind as in front, they are the ones to sell.

For half grown puliets the wider they are behind and the more they taper forward the better layers they are when they are old enough. High and rounding at the top of the head on any breed of chickens, and see that they are not too low on top of the head. Arother point for a laying hen is when the bone where the egg passes through is closed, they are not laying and when it is opening up they are getting ready to lay and when it is open they are layıng. This can be told by examining the hen. 


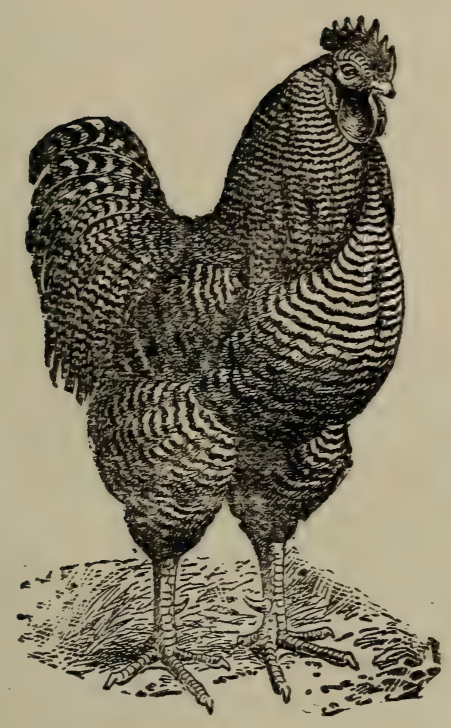

THE BARRED PLYMOUTH ROCK

A yellow bill, a yellow limb and a limb with a heavy bone. A low fetlock. The bars should be barred clear to the skin all over. If the feathers are white an inch from the skir they are not fullblood. See that there are no cotton feathers at the top of the limb and under the wing They must have a long toe and a fat heel. 


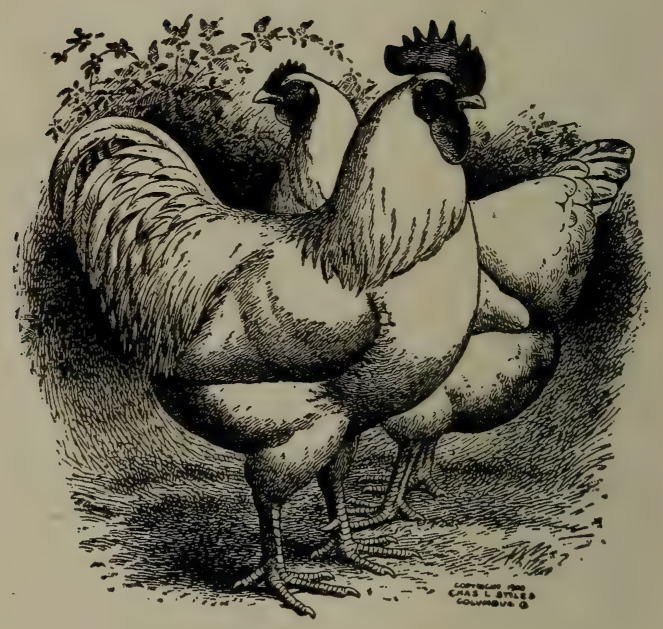

THE WHITE PLYMOUTH ROCK

They s hould be pure white all over. Look for colored feathers in the wings and tail. 


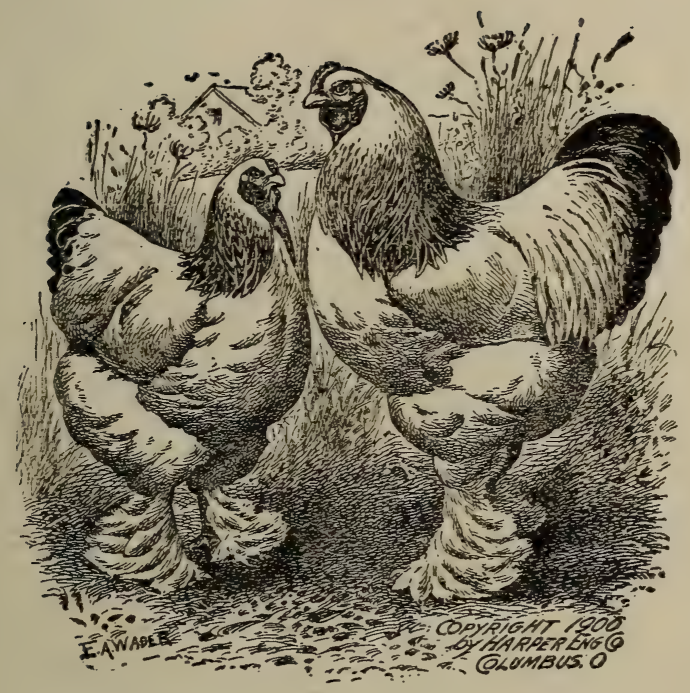

THE FULLBLOOD BRAHMAS

Look for the same style and some of the same points on the Brahma as on any other breed. Black and white feathers on the neck down to the wing. A little black under the wing. A low fetlock. A heavy limb and well feathered. A yellow bill. 


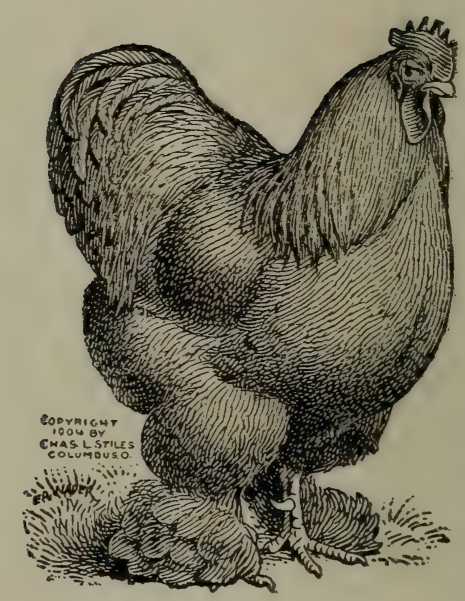

\section{THE FULLBLOOD BUFF COCHIN}

Are yellow all over. A heavy limb and well feathered. Look for the same style as in other fullblooded chickens. Be careful not to get too many black feathers in the tail for fullblood. 


\section{POULTRY}

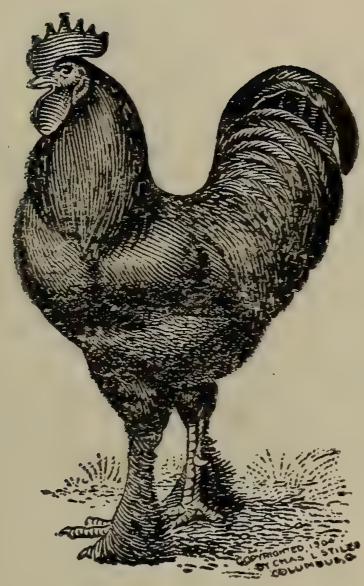

\section{THE LANGSHANG}

They are a black chicken, the bill is not so yellow, long red gills, a heavy comb, black down to the wing and on down to the limbs, with blue black wings and long black feathers in the tail, a low fetlock and a large foot. Also extra heavy limb and heavy feathered. 


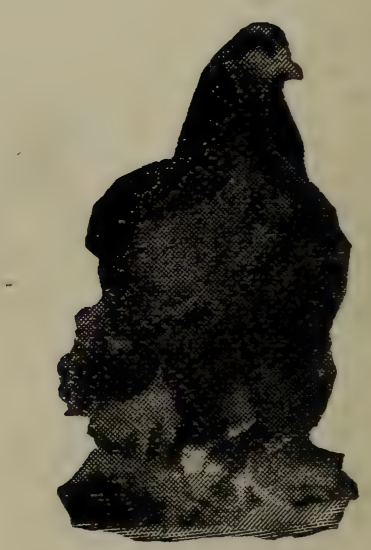

\section{THE PARTRIDGE COCHIN}

They are a dark chicken which shows yellow at the neck and black specks over them, with a yellow bill, heavy gills and heavy comb, a large foot, low fetlock and an extra heavy limb and also heavy feathers. When picking a Partridge Cochin crower be careful and not pick him too red and look for the points. 


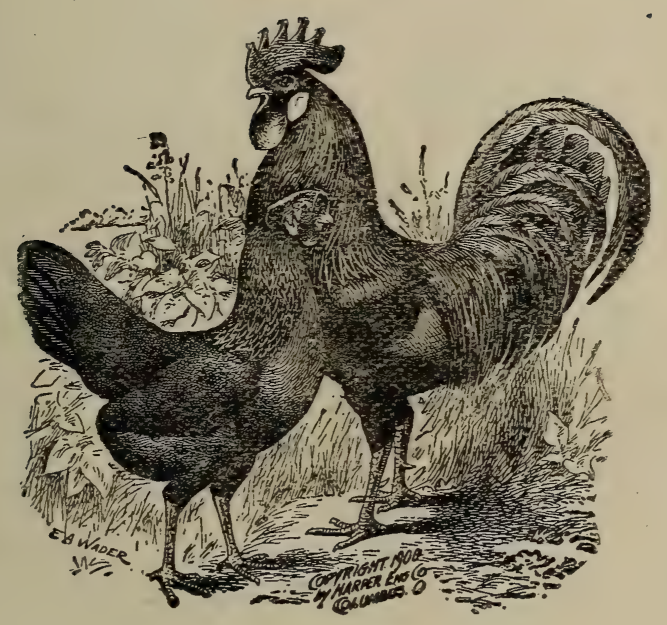

\section{THE BROWN LEGHORN}

They have a yellow bill, five points on the comb, a white ear, a brown color te the wing and also down to the limb below the wing, with a blue black wing and the tail feathers black, a low fetlock, heavy yellow limb a long toe and a fat heel. 


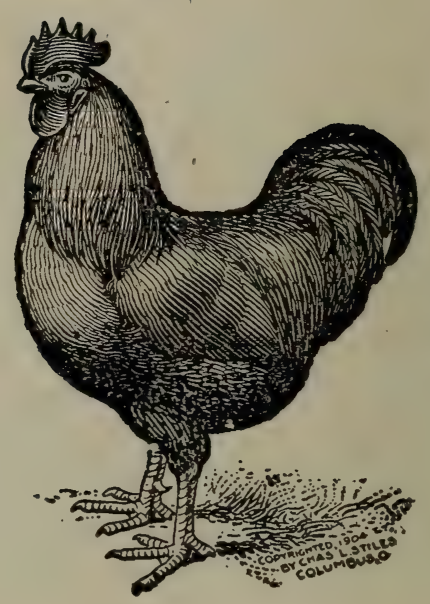

THE FULLBLOODED RHODE ISLAND REDS

A yellow bill and a yellow limb. Red down the neck to the thighs. Red wings, and some black feathers in the tail, also a few black feathers under the wing. Look for the same style as in other fullblooded chickens. 


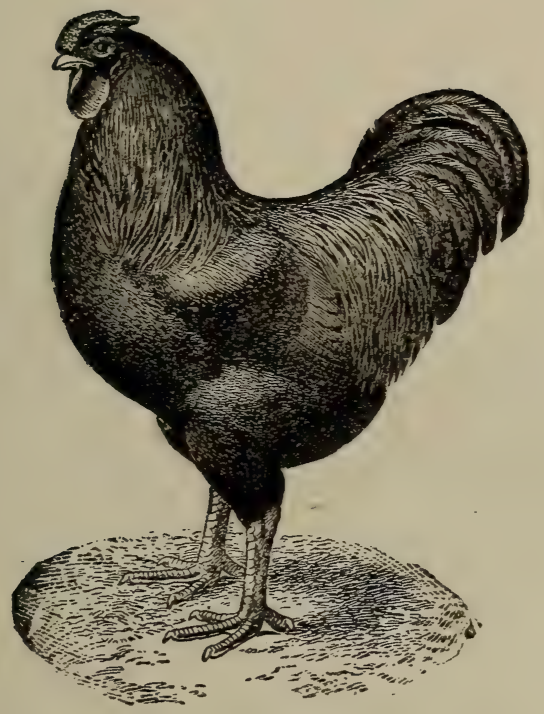

\section{THE FULLBLOODED BUFF ORPINGTON}

A blue bill and a blue limb. Top of toes are blue and the bottom of the feet is - blue for a fullblood. If the bottom of the foot is vellow they are not fullbiood. They are crossed with the Minorca. Some have a single and some a double comb. 


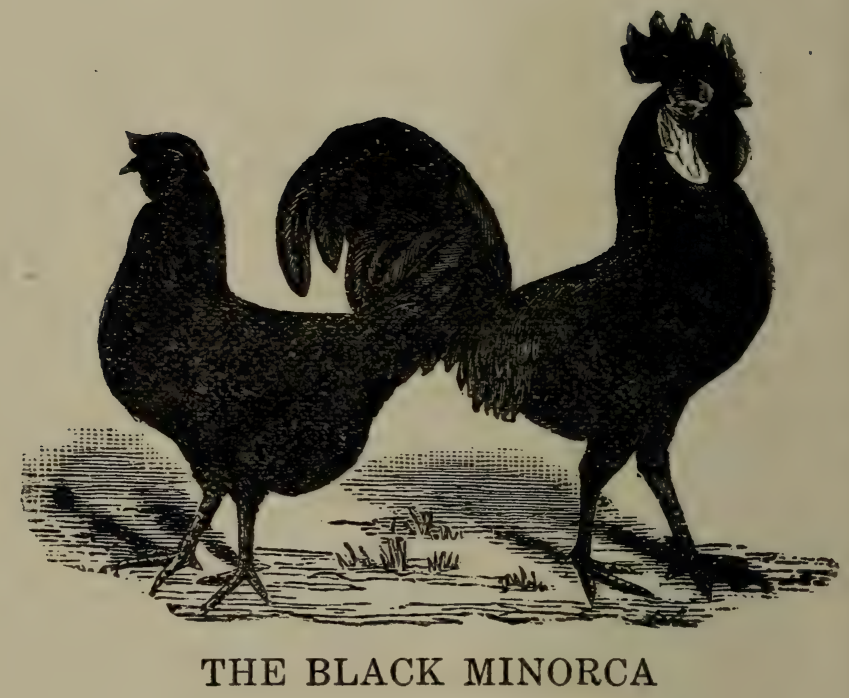

They have a blue bill and a long red gill, a white ear and are black from the neck down to the wings and under the wings to the thighs with a blue black, shining wing and long black tail feathers. 


\section{POULTRY}

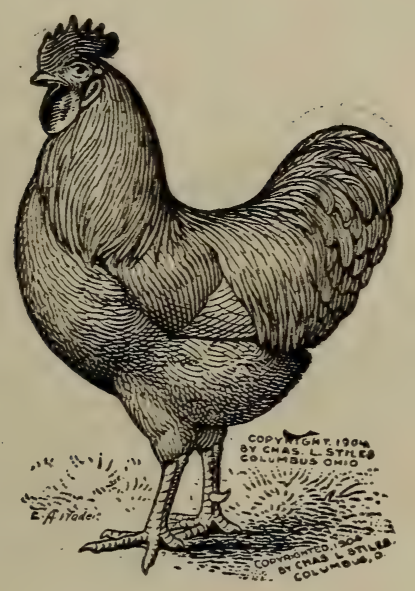

\section{THE BUFF ROCK}

They are yellow. No black feathers in the wings but a few on the tip of the tail. The points on the limbs, toes and bill are the same on the three breeds. 


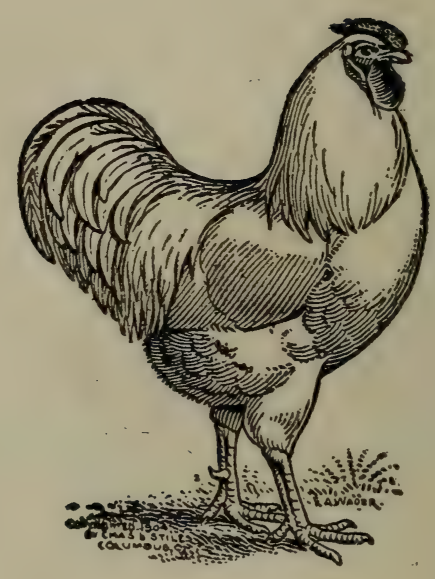

THE WHITE WYANDOTTE

They have a yellow bill, long red gills and a split comb which lays both ways, also a heavy yellow limb and long toes, a fat heel and low fetlock. Always look for brown feathers in the wing and tail. 


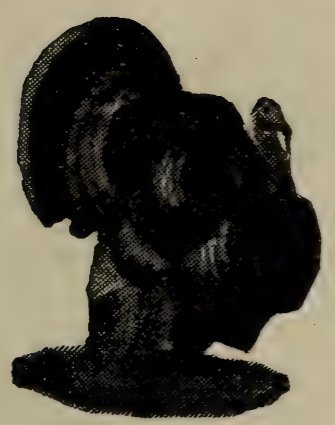

\section{THE FULLBLOOD BRONZE TURKEY}

Lots of red on top of the head. The gills long and red. Black down in front under the wings clear to the limb. A blue bill and heavy blue limb. Long toes and fat heel. Blue black wings. Small white bars in the tail. 


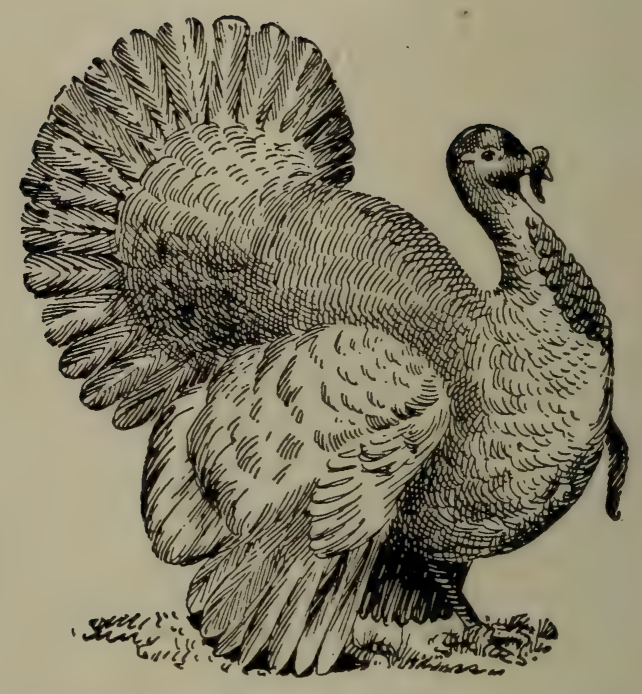

\section{THE FULLBLOOD WHITE TUKKEY}

A yellow bill. The top of the head and the gills a pale red. The limb is yellow. The feathers are all white. When there are black spots on the white turkey they are crossed with another breed of turkey. It can be told in the wing. 


\section{POULTRY}

Breeding.---It is taken for granted that, whether the object is simply to raise a few fowls for home use or to embark in poultry raising as a business, the advantage of thoroughbred fowls over dung-hill varieties áre manifest.

The scrubs will eat as much as the improved breeds. The latter are, in general, much heavier, finer and hardier; they lay more and richer and larger eggs; they come to maturity sooner, are far more quiet about the place, and both the eggs and dressed poultry bring more in discriminating markets. There is a large and constantly growing profit in selling pure bred fowls and eggs for breeding; and finally, they are a satisfaction and not an eye-sore to have in sight.

Since the breeding of poultry involves exactly the same general principles that underlie the successful breeding of all stock, nothing could better teach the farm. er's boys, when older, how to manage cattle and horses. It will keep them in pocket money and out of bad compeny. What breeds to keep depends on where 
they are kept, and for what purpose. Look over the breeds, make your choice and send for a pair or two to some breeder. It pays to get the best. As a rule, the best results are produced by mating so as to balance the defects on one side with all serious defects in either.

To secure uniform type and color in breeding, selest the cock for his beauty or shape and color, and the hen for her egg productiveness, constitution and vital force.

Do not breed from cocks with less than seven-eights of the blood of the strain, or from hens with less than three-fourths. With Asiatics, give one cock to nine to thirteen hens. With smaller breeds, twelve to forty.

Cure weak legs and all other constitutional defects with hatchet.

Cross bred fowls are generally much more prolific as egg producers than either scrubs or thoroughbreds.

The most usual practice is to improve common stock with pure blood, but care should be taken not to breed from the cross. 
Feeding and Care.-If only a few fowls are kept, and those in the country, where they can forage for themselves, the scraps from the table will generally furnish about the right amount in variety and quality of food.

Where large flocks are kept in yards, and during cold weather, more feed is needed. In sumımer feed scalded corn meal and bran for breakfast, and any kind of grain at night. In winter boil meat scraps, potatoes, turnips, etc., together and feed warm.

Corn fattens, but is not best for laying hens, wheat and buckwheat being better. Fowls must have plenty of gravel or old mortar and some kind of green foodgrass, lettuce, etc., the year around. In winter chopped caubage and second growth clover must take the place of grass. Give them plenty of pure water and keep the drinking vessels clean.

Do not over-feed or allow feed to lie about, and always scatter the food on the ground or on the floor, never lumping it in trough or 'pan. 
Chicks should in particular be kept hungry and lively. If too fat they neither lay well nor are the eggs liable to hatch. Do not place too many chicks together in cold weather, for they get too warm and take cold and die.

Hens for Laying.-They should be kept in droves of not more than twenty or thirty of the larger breed, and forty or fifty of the smaller. They lay as well without a cock, and the eggs keep longer.

The proper conditions for the manufacture of the eggs are warm, dry and clean quarters, air and exercise, and plenty of good stimulating food, furnished by nature in summer; if artificially provided in winter will unfailingly produce the same result.

Todd's Tonic Food is an excellent preparation for keeping the hen in order and stimulating her to lay herself out. Pulverized cayenne pepper mixed with the fond every other day, one teaspoonful to each twelve fowls, is good also as an egg stimu. lator.

Feeding Chicks.-For the first week or ten days feed the chicks stale bread soaked 
in scalded milk, and occasionally boiled chopped eggs, millet or canary seed.

Follow this with scalded corn meal, mixed with cracked corn or wheat, grass if it can be had, or chopped lettuce or cabbage, an occasional meal of meat or boiled fresh fish. Give plenty of pure water in clean dishes several times a day.

Feed Asiatics all they will eat.

Keep chicks dry or out of wet grass. Avoid huddling. Twelve or infteen are enough for one coop.

Do not take the hen away till she weans the chicks herself.

Disease and Treatment.-Prevention of the disease is easier than the cure. Sickness, in ninety-nine cases out of one hundred, is caused by dirty, lousy quarters and poor ventilation, bad water and food, and too close confinement.

The best remedy in cholera, roup, chicken-pox and diphtheria is to instantly kill and bury the affected fowl, and attend to the sanitary condition of the remainder.

Coal oil, mixed with corn or soft food, 
and fed to fowls once or twice a week is a good preventive of disease.

Lice and the dreadful red spider are deadly pests of the chicken house. They may be killed or driven out by pouring spirits of turpentine or coal oil on the roosts and in cracks and crevires.

Do not put either on the bodies of fowls, but dust carbonate of lime or snuff among their feathers.

Moth balls placed in hen's nests and coops are good to drive away lice.

Onion peelings placed in nests are good to drive away lice.

Scurvy Legs-Should be rubbed with a mixture of sulphur and lard.

Bumble Foot-A bruised and puspuffed condition of the foot, resulting in lameness.

Caused by heavy fowls jumping and flying from roosts npon gravel, stones, etc.

Treatment-If discovered before the pus congeals, lance the swelling at the front and rear of the foot and press out the pus and inject a solution of carbolic acid and water. When the pus has congealed, use a strong liniment and let the inflammation settle down into a corner. 
Cholera.-A contagious and very fatal disease of the bowels, death usually resulting in $t w \in$ lve to thirty-six hours.

Symptoms.-Sudden and violent thirst, severe purging, the droppings being at first greenish, afterwards thin and whitish, the fowl becoming extremely weak, staggering and falling with indications of cramp.

Caused by filth, confinement, over-crowd. ing, impure water and food, or exclusive corn diet.

Treatment.-Remove the fowls and purify the ronsts, -houses and nests with hot whitewash, with a little carbolic acid added. Clean up the droppings and sprinkle the floors with fresh dug earth and slacked lime every day.

Use all the sanitary precdutions previously recommended, plenty of fresh water and access to burned bones, shells and charcoal. Feed twice a day, soft feed in the morning, dry grain at night. Let the evening feed be corn soaked in carbon oil three to five times a week. Salt the feed occasionally, and put alum in the water. 
Strong smartweed tea for drink and soft food is also recommended.

Canker and Diphtheria.-An obstinate contagious disease, affecting the mouth, throat, nostrils and eyes. - Somewhat analagous to croup.

Symptoms.-Face and throat are very red and inflamed; the latter becomes coated with a yellowish leathery lining, which, on being removed, leaves the surface a whitish red, thickly studded with raw spots.

Ulcers form in the mouth, nostrils and eyes; diarrhea, with greenish discharge; extreme exhaustion.

Caused by taking cold, damp quarters, etc.

Treatment.-Wasin and steam the head with hot water, to which a dash of carbol ic acid has been added; sponge out the throat with carbolic water and gargle with a strong solution of potash.

Give three grains of hyposulphite of soda, in milk, in the morning and three grains of quinine in the evening. 
Feed cn brandy and raw eggs, or bread soaked in whiskey or ale. Remove to dry, warm quarters.

Diarrhea.-A morbidly frequent evacuation of the intestines, the scourge of young chicks in early spring.

Caused by improper food and lack of corn.

Treatment.-Give chicks nothing to eat but scalded milk and cook all feed.

For older fowls, a tablespoonful of castor oil and ten drops of laudanum are effectual.

Feed bread soaked in scorched milk and black pepper, and supply plenty of burned bones and charcoal.

Gapes.-Worms in the throats of chicks.

Symptoms.-Gaping and stretching out the neck, accompanied by lassitude.

Caused by impure and stagnant water.

Treatment.-Keep camphor constantly in drinking water. Cover the bottom of the coop with lime.

Take a hen's tail feather, strip it to 


\section{POULTRY}

within an inch of the end, wet the tip with a solution of-Cdrops of carbolic acid and one ounce of glycerine, run the feather down the windpipe,twist it sharply around two or three times and draw quickly out. Turpentine may be used in the same way. The worms will adhere to the feather; use a new feather.

Another remedy is to put the chicks in a covered box and bore a few holes in the bottom and place over a box with sulphur and set fire to the sulphur and smoke the chicks for a short time.

Roup-Chronic catarrh, resulting in consumption; highly infectious.

Symptoms.-The skin hanging from the lower beak is inflated and emptied at every breath; watery, frothy and offensive discharge from eyes and nostrils; a congealed yellow coating to the mouth and tongue.

Cause.-Exposure to cold and dampness, housing in foul, ill-ventilated and tainted quarters, gorging after a fast.

Treatment.-Remove the affected fowls, disinfect and fumigate the quarters, and give the remaining ones a tablespoonful of 
flour of sulphur to every fifteen fowls every day for a week, feeding eight drops of tincture of iron in soft food to each hen every other day.

Wash and steam the heads of sick ones with hot water containing a dash of carbolic acid.

Clear the nasal passage with carbolic acid and water and gargle the throat and mouth with a solution of potash, but do not remove the canker. Repeat this daily, and give each morning a gill of milk in which three grains of hyposulphite of soda have been dissolver, and each evening a gill of milk with eight drops of tincture of iron. The milk may be poured down the fowl's throat by taking hold of the under beak and drawing the neck upward until straight. When the fowls begin to im. prove, give nourishing food, with occasional doses of sulphur.

Another Remedy for Gapes. -Take camphor gum about the size of a pea, melt with teaspoonful of lard, take a broomstraw and drop in the throat. 
To Kill Lice.-Take strong salt water, boiling hot, and sprinkle about the coop and where the chickens run.

To Keep Chickens Healthy.--Use the horse, cattle and chicken powder as the directions say.

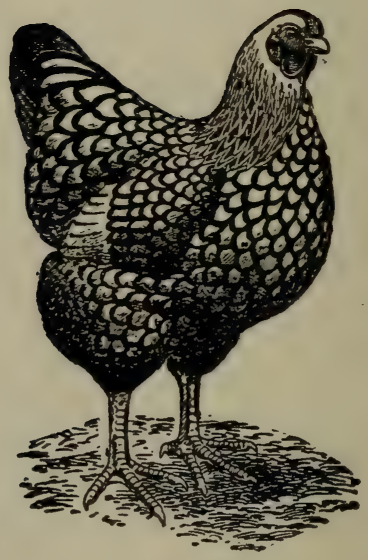




\section{JACK}

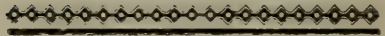




\section{JACK}

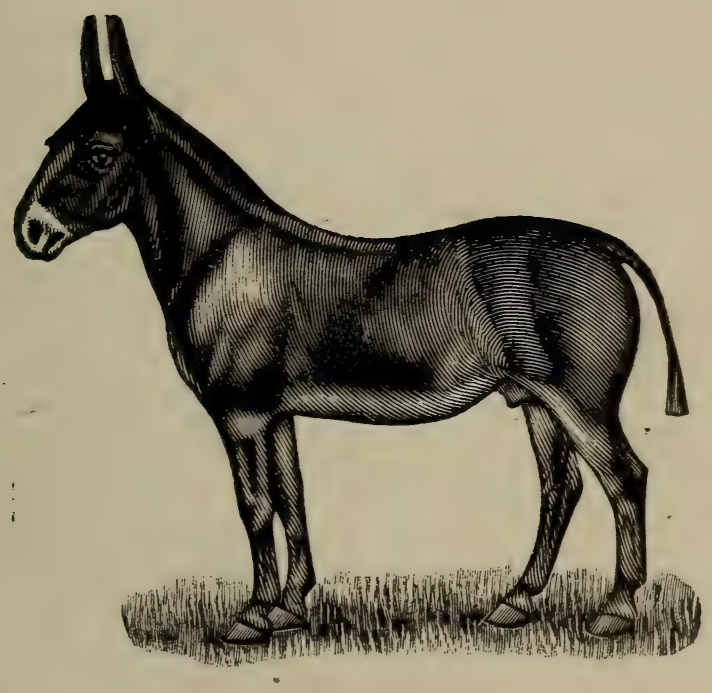

WHAT TO LOOK FOR IN A BREEDING JACK

A long ear. Heavy close to the head. Not too narrow between the ears. Wide between the eyes. IVide on down below the eyes. Broad across the nostrils and not too narrow in the mouth. A wide 
bone in front and behind. A good heavy front knee and not too near cut off below the knee. Wide across the withers.- Long in the back. Wide in the kidnevs. Not too steep in the rump. Heavy bone in the tail. Low flank. Wide in the stifle. Fair length from the girth back. Wide from the stifle to the knee and a broad knee. A flat limb. Not too much flesh in front of the pastern joints. Stand squarely on his limbs and not too far apart.

A Sure Jack. - The closer the privates are to the sheath and the nearer one size, the surer they are. When one private is so much larger than the other, there is where the weak colts come from. The farther back the privates and the lower they hang, the less sure. When both privates are large, this is a good point for a slow Jack.

A Slow Jack in Covering.-Make the platform in the stall and when you have the mare in her place and by the time you have everything ready he will be ready. If you want him to have a little more snap take a handful of flour and put in a pan 
jaw. Not too small in the throatlatch. A good wide shoulder. Wide between the shoulders. Not too wide between the front limbs. A fair sized foot. Heavy and put water in, and stir so that it is a little thin. This will not hurt him, it will do him good. The larger the wart is above the knee the more power it shows in a strong breeder.

\section{IN BREEDING JENNIES}

Try them with a Jack early every morning, and breed the first time they come in for a Jack Pick the Jenny as the Jack in the makeup.

\section{WHEN BUYING MULES}

Buy them under the same points as the Jack outside the sureness in the breeding points. The larger the wart above the knee, the more power the mule has, and the wart small above the knee, the chances are, they are handy on their feet. 


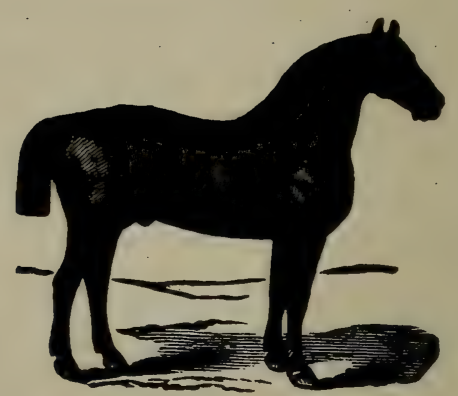

\section{THE HACKNEY}

This is a good coach horse, arera ge size pienty of vim; very healthy. This horse has very straight hind legs and is generally black or brown in color; well made; carry their heads well up and are smooth travel ers. Breed them with the German Coach for good knee action.

Points For A Sure Stallion.-Tine surer he is the closer the privates to the sheath and the nearer one size. One private larger than the other is a point for weak colts. The farther back and the lower the privates is $\bar{x}$ point for an un- 
sure horse. Watch these points closely, for a draft horse is not as sure as a light horse. Look for the draft points on stallions or colts. A heavy wart at the fetlock and the larger around the wart above the knee; that bone directly below the ear heavy, a heavy bone between the ears. The heavier these points are the more draft on horses or colts. These points are for sure breeding on draft and trotting horses, also Shetland ponies, for all stallions.

In Buying or Trading a Horse, Don't be Too Quick.-Trade slow and watch close to see all the blemishes. Watch for heaves, and wind-suckers, and air-suckers; look for lumps about the neck, or about the head or the whiskers; feel along the neck and under the mane for lumps, and to see whether he has been bled.

Those little lumps that yellow water comes out of is caused from overheating. The first start of it is button farcy.

Stringy.--A horse raises his hind feet. Springy.-A horse raises his front feet 
and hind feet. He can't stand still. The leaders tremble from weakness.

Another Measure for a Horse.-From the point of the hip bone to the point of the breast bone should measure the same as from the stifle to the front of the withers, also from the stifle to the breast bone should measure the same as from the coupling to the hock. In other words they should all measure alike if a horse holds out its measure. If the measure from the coupling to the hock and also longer from the stifle to the breast bone this shows speed.

How to Find the Height of a Colt or Old Horse.-Four times the length from the center of the knee to the top of the hoof will give the height of a colt or old horse.

To Measure a Horse.--Take a string and measure from the shoulder bone to the top part of the hip and take half the length of the string and start from the center of the line and measure to the center of the belly. On a fat two-year-old colt this measure 


\section{HORSE}

will hold out when he is a horse if he is fat.

How to Measure a Horse From Two Years Old or Older.-Four times the length from the middle of the front knee to the top of the hoof is the height of any horse when it has its growth.

How To Measure a Horse's Head; Whether It is Well Proportioned. For Instance Too Long or Too Short.-It should be the same measurement from the top of the neck to the throttle as from the top of the mouth to throttle, also from the throttle to the lower part of the eye in front, and from the throttle to the bottom part of the ear in front.

How to Measure a Horse that will Hold out His Measurements. - When they have the same mcasurement from the point of the hip bone to the point of the breast bone as from the front part of the withers to the stifle, also from the stifle to the point of the breast bone as from the coupling to the hock. When a horse is longer from the stifle to the point of the breast bone it 
shows speed. And when they are longer from the coupling to the hock, it also shows speed.

Recipe for Wire Cut on a Horse.-Verdigris, mix with lard to make a paste. Put on the cut twice a day.

How to Breed.- - Some breeders advocate breeding in and in, while others argue cross breeding. This can be decided only after careful study and governed largely by the object in view. In and in breeding is breeding members of the same family, and certainly requires a gifted mind to make it successful, because the success depends on the careful selection of the parents.

Some persans think that in-breeding is brother and sister but it is not. It is breeding in the same family but from different dams. For instance, the Hambletonian and Wilkes are the same family but different dams.

For a young or inexperienced breeder the in and in breeding is dangerous experiment. It should never be undertaken inless backed by thorough study and 
years of practical experience. While crossbreeding demands good judgment in the mating, yet it is safer for the average breeder than the in and in breeding.

Selection of Breeding Animals.-In making selection of sire or dam it is well to take into careful consideration vigor, intel ligence, muscular power, and above all, perfect soundness in limbs, body and inter. nal organs. These matters must not be overlooked if you desire good foal. You cannot be as successful in th 2 breeding of horses unless you have an intelligent conception of the subject in all its details and requirements. For farm work or heavy draft horses the gait to be most desired is a fast walk. Owners of farm or draft horses would save themselves thousands of dollars anrually if they would carefully cultivate the fast walk. It would be more valuable to the world in general than hundreds of two minute trotters.

How to Tell When a Mare is With Foal.Take a rope or strap and measure around the girth where the harness goes on the 
back and the belly-band buckles on them. Measure just in front of the hind legs around the body. If larger than that of the first measure you may be sure she is with foal.

Care of Mares With Foal and Care of Colts. - A mare in foal not intended to be kept at work should not be turned into too rich pasture, as it disagrees with her stomach and makes her too fat. Be careful of this or she may have a miscarriage. Then again if the pasture be too poor the mare will get too thin and will starve her foal in its growth. If she has been highly fed she should have a feed or two of oats daily. After she is six months gone hay and oats should be fed. After the colt is born the mare should have a bran mash.

How to Make a Mare Own Her Colt.To make a mare own her colt, take some milk from the mare and rub it on the colt's nose, then let the mare smell it and she will own the colt at once. It will work like a charm.

Feed the colt plenty of bran and oats. It will make good bone. 
HORSE

173

Liniment for Thoroughpin or Bog Spavin.-Alcohol, 4 oz.

Camphor, I oz.

Hartshorn, I oz.

Spts. turpentine, I oz.

Arnica, I oz.

Oil of spike, I $\mathrm{Oz}$.

Oil of cedar, I oz.

Recipe for Colic or Cramps.-

Whiskey, $\frac{1}{2}$ gal.

Soda, $\frac{1}{2} \mathrm{lb}$.

Turpentine, $\frac{1}{2} \mathrm{pt}$.

Aloes, 2 oz.

Gum camphor, $2 \mathrm{oz}$.

Salamoniac, 2 oz.

Take one half of the above recipe, put in a jug and shake. Give two or three ounces in warm water.

Black Liniment for Distemper.--

Alcohol, 4 oz.

Spts. camphor, $4 \mathrm{oz}$.

Aqua ammonia, $2 \mathrm{oz}$.

Oil spike, 2 oz.

Spts. turpentine, $+\mathrm{oz}$.

Rub on throat for distemper. 
Spavin Cure.--

Powd. cantharides, 2 oz.

Gum euphor bium, $\frac{1}{2}$ oz.

Corrosive sublimate, $\frac{1}{2} \mathrm{oz}$.

White vitriol, $\frac{1}{2} \mathrm{oz}$.

Spts. turpentine, I oz.

Spts. ammonia, $\frac{1}{2} \mathrm{oz}$.

Tr. iodine, I oz.

Nitric acid, I oz.

Lard, I Ib.

Use one-haif of the recipe. Cut the hair as short as you can. Rub with hand till it gets warm; grease around with lard; put the liniment on three times twelve hours apart; wash with castile soap and grease with lard. If $\mathrm{n}$ ot cured, repeat in six days.

For Lung Fever. - Take bran and soak in water; let the horse urink the water; give plenty of salt to keep down inflammation and to keep the lungs open; take a piece of carpet 3 or 4 double and pour on hot water. For pleurisy or lung fever, shave hair off short and apply a mustard plaster made very strong.

Give five 3-gr. capsules quinine in the 


\section{HORSE}

morning, 20 drops aconite in the evening in one gallon of water. If the horse will not drink it, drench with it.

What a Grade Horse Is.-He is a fullblooded horse, but they are picked over. Say there are ten fullblood horses of any breed. One man will pick out what are shown as the breeding points and the show points. Another man will come along and pick two the same way. Another man will pick one or two horses. The balance are grades-are picked over yet they are fullblood, and can be pedigreed. Take one of these grades and they will breed different colors and different shapes. A man can buy one of these horses and go back where people think a horse with a pedigree is the correct animal and if bred to a mare will show a fair colt. Any animal that is picked over is a grade.

Horse ought to have about a thimble full of salt in his feed twice a day.

Cattle want to be salted same way to make good butter. Salt is a purifier. 
Horses will breed back ten generations. That is where the grades show up the best. Cattle will breed back eight generations. Hogs will breed back six generations. Sheep will breed back four generations. Chickens will breed back four generations.

Sheep and chickens can be breed up so they will show good breeding in four generations.

In castrating any kind of stock use hot salt water in case they swell and afterwards some dry salt.

This book is condensed, and will prove handy and easy to understand to anyone. 


\section{INDEX}

Page

THE HORSE

Coach

Silvertail Morgan

Percheron

Shire

Cleveland Bay

Black Hawk Morgan

Hambletonian

Clydesdale

Norman

Running

Saddle

Shetland Poney

Shetland Brood Mare

Points to look for in buying a horse

Mooneyed or Weakeyed

Pollevil or Fistula

Thick Wind

High Bred Trotting . . . . . 17

Eligible to register $\quad$ • . . . 18

Draft Brood Mare . . . . . 18

Draft Stallion . $\quad . \quad . \quad . \quad . \quad .19$

How to tell age . . . . . 20

Points for good wind on track horse . . 21

Bad Wind . . . . . . 21

Gravel or Irritation of Bladder ․ . . 21

To Remove Warts . . . . . 22

Thrush . . . . . . . 22

Fevered Leg $\quad . \quad$. $\quad . \quad$. $\quad 22$ 
Big Head

Proud Flesh

To find if Horse is Lame in Foot . . 24

To make Horse look Sleek . , . . 24

To grow Hair on an old Sore $\quad$. $\quad$ • $\quad$. 24

Chills

To grow Hair on Mane or Tail . . 24

Poison _ . . . . . . . 24

Corns . . . . . . . 25

Side Bone . . . . . . . . . $\quad$. 25

Ring Bone . . . . . . . 25

Scratches and Grease Heel . . . 25

For Pinkeye and Distemper $\quad \ldots \ldots \ldots . \quad 26$

Shock for Horse or Cattle $\quad$ • $\quad$ • $\quad$ • $\quad 26$

Rheumatism . • • • @ 27

Mexican Mustang Linimunt _ . . 27

Stringhalt Remedy _ . : . . 27

For Wire Cut or Kick _ _ . _ . 27

Ointment $\quad . \quad . \quad . \quad . . .28$

To Stop Wound Bleeding $\quad$ • $\quad$ • 28

Heaves . . . . . . . . 28

Sweeney . • • • • • . . 28

Thoroughpin $\quad$ • $\quad$ • $\quad \cdots \quad 29$

Valuable Recipes . . . . 29 to 37

Ropes and Bridles for Control of a Horse-

For Kicking, Leading Rearing, Jump-

ing and Running away . . 37 to 59

CATTLE

Jersey

Holstein

Roan Durham

Poll Durham

63

Roan Durham Male _ 66 


\section{Hereford}

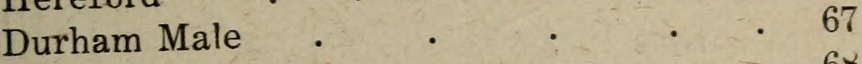

Aberdeen Angus - . . . . 68

Jersey Male • • • • • • • •

Picking Beef Cattle _ _ . . 69

How to tell High Bred Cattle . . . 70

How to tell a Good Milk Cow . . . 70

Points on a Good Milk Cow _ . . 72

Raising Calves

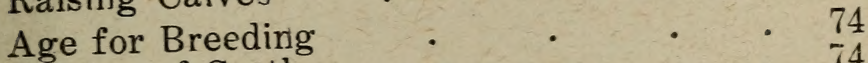

Disease of Cattle

Garget

Milk Fever

Lock Jaw

$\begin{array}{ll}\text { Lock Jaw } & 79 \\ \text { Treatment of Cow before and aft }-\mathrm{r} \text { C tlving } & 80 \\ \text { To tell age of Cattle } & 81\end{array}$

Points for a Good Milk Cow . . $\quad$\begin{tabular}{l}
87 \\
\hline
\end{tabular}

\section{SHEEP}

Merino

Southdown

Southdown
Cotsw Jld
Shropshire and Cotswold erossed

The Young Lamb

Weaning Lambs . • • • $\quad 98$

Tagging and Docking . . . . . . 100

Scab

Graft

Ticks

Grubs

To break a dog from Killing Sheep $\quad: 105$

HOGS

Male $\mathrm{Hog}$

Poland China

Duroc and O. I. C.

Duroc and O. I. C.
Chester White and Berkshire $\quad . \quad . \quad . \quad 112$
Essex and AcGee 
To prevent Hog Catching Chickens _ - 116 Crossing Hogs Physic Hogs

Lice

Feeding Pigs
Care of the Brood Sow
B

Breachy Hog

Thumps

POULTRY

Barred P. R.

White $\mathbf{R}$

Brahmas

Buff Cochin

Langshang

Partridge Cochin

Brown Leghorn

Rhode Island Red

Buff Orpington

Black Minorca

Buff Rock

White Wyandotte

Bronze Turkey

White Turkey

Breeding, etc

Hens for Laying

Feeding Chicks

Scurvy Legs

Cholera

Lice

JACK

Sure Jark. Breeding Jennies

130

Hackney Horse

Points for Sure Stallion

135

$1^{\circ}$

To Measure a Horse

How to Breed Horses

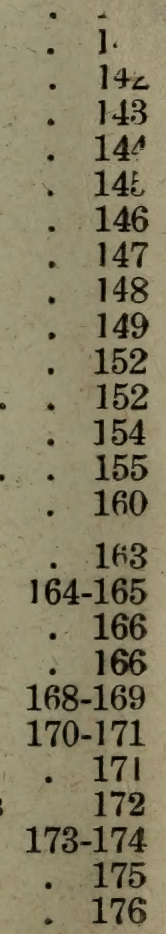

How to Tell When Mare is in Foal

Care of Mares in Foal and Care of Colts

Recipes

What a Grade Horse Is

Breeding Back

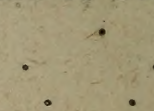


One copy del. to Cat. Div. APR 2 EEQ? 


\section{LIBRARY OF CONGRESS}

\section{THIS}

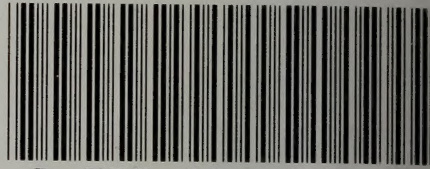

00008990621

Is for the use of those who buy it, so that when they need it they will have it

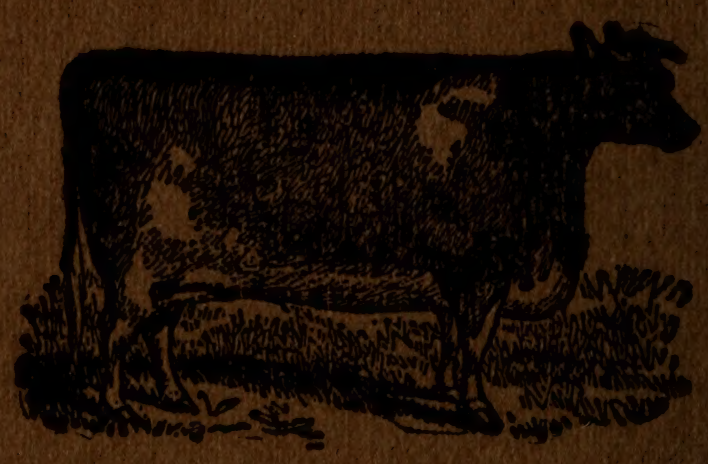

